\title{
Polynomial Regression and Response Surface Methodology: Theoretical Non-Linearity, Tutorial and Applications for Information Systems Research
}

\author{
Darshana Sedera \\ Monash University \\ Australia \\ darshana.sedera@gmail.com
}

\section{Maura Atapattu}

University of Queensland

Australia

\section{Abstract}

Information systems (IS) studies regularly assume linearity of the variables and often disregard the potential non-linear theoretical interrelationships among the variables. The application of polynomial regression and response surface methodology can observe such non-linear theoretical assumptions among variables. This methodology enables to examine the extent to which two predictor variables relate to an outcome variable simultaneously. This paper utilizes the expectation confirmation theory as an example and provides a methodological commentary that illustrates a step-wise process for conducting a polynomial regression and response surface methodology.

Keywords: Quantitative analysis, Polynomial regression, Response surface methodology, Non-linearity

\section{Introduction}

Non-linearity of variables is a key underlying assumption in most research conducted in information systems (IS), where the researchers assume that there is no interplay between variables. This approach is particularly important in multi-source feedback research, where it allows a researcher to examine the extent to which the combinations of two predictor variables relate to an outcome variable (Shanock et al. 2010). For an example, the technology acceptance stream of research, which have been developed using the theory of planned behaviour (Ajzen 1991) and theory of reasoned action (Ajzen and Fishbein 1980), highlight non-linearity. Both these theories and their derivations like unified theory of acceptance and use of technology, require the researcher to consider non-linearity of the constructs. Similarly, the expectation confirmation theory (ECT) (Oliver 1977; Oliver 1980; Oliver et al. 1994) is also a widely employed theory in IS research (Lim et al. 2013), with non-linear assumptions.

Despite such theories requiring non-linearity, IS research rarely treats them as linear theories. For example, Venkatesh and Goyal (2010, p. 282), citing Technology Acceptance Model and Expectation Confirmation Theory", state that "prior technology acceptance research in general and EDT research in IS in particular is limited to linear models. Linear models fail to reveal complexities that are anticipated in theories of congruence, such as EDT in which attitudes and behaviors result from

\footnotetext{
${ }^{1}$ A representative collection of past information systems (IS) studies employing ECT include (Fan and Suh 2014; Lankton et al. 2014; Lankton and McKnight 2012; McKinney et al. 2002)
} 
the congruence between expectations and experiences." Failure to adhere to the non-linear assumptions compromise research and practical explanations of the research, compromising the credibility and insightful findings. Moreover, such linear models assume that there is a similar effect for multiple independent variables on the dependent variable (Venkatesh and Goyal 2010). Therefore, even if the actual relationship between the component measures and the outcome measure is curvilinear, linear models would oversimplify the relationship and mask the true relationships among the variables (Edwards 2002; Edwards and Cooper 1990). (Fan and Suh 2014; Lankton et al. 2014; Lankton and McKnight 2012; McKinney et al. 2002)

Polynomial regression (Edwards and Parry 1993) and response surface methodology (Box and Draper 1987; Khuri and Cornell 1987) have been acknowledged as techniques that allow researchers to engage in testing the non-linear assumptions, allowing greater exploratory and explanatory potential of the phenomenon under investigation. Specifically, the polynomial regression (Edwards and Parry 1993), together with the response surface methodology (Box and Draper 1987; Khuri and Cornell 1987), provide the basis for testing and interpreting the features of surfaces corresponding to polynomial quadratic regression equations between two predictor variables and an outcome variable (Shanock et al. 2010). The non-linear analysis provides an opportunity to investigate beyond the simple relationships between two (or more) variables and extend the understanding of the interaction effects of the variables.

The theoretical simplification through linearity assumptions not only hinder the possible opportunities to better understand how complex relationships between variables unravel, but also carries the dangers of mis-interpretation and/or overstating the effects, ultimately leading to incomplete, partial or erroneous interpretations of the findings (see Ping 2002; Titah and Barki 2009). Naturally, the employment of non-linear postulations in analysis has the potential to uncover the complex and contingent relationship that the theory originally suggests between the constructs.

Despite the aforementioned advantages, only a handful of IS researchers have employed the polynomial regression and surface response technique in their analyses (See Brown et al. 2008; Roberts and Grover 2012b; Titah and Barki 2009). This paper attributes the paucity of studies that relax linearity assumptions to (i) the conceptual challenge of theorizing complex three dimensional non-linear relationships, (ii) interpretive difficulties of the results and (ii) the limited existence of discussions on the method.

As such, the objective of this paper is to present: (i) the applicability of the polynomial regression and surface response technique to the main-stream IS research, (ii) how new research questions and insights can be derived using the polynomial regression and surface response technique, (iii) guidelines for developing hypotheses corresponding to two related predictor variables and their dependent variable, (iv) the procedure to conduct a polynomial regression with its corresponding response surface graph, (vi) an application of the methodology in a field setting and (vii) the benefits of the polynomial regression and response surface methodology.

The paper proceeds in the following manner. First, the paper provides an overview of polynomial regression and response surface method. Therein, it introduces the assumptions and interpretations of the method. Next, it provides results of an analyses demonstrates the assumptions and interpretations, employing the expectation confirmation theory. It provides a step-by-step application of the methodology, as well as how the results can be interpreted. Finally, the paper concludes with the contribution to academia and practice. 


\section{Background}

The use of polynomial regression together with response surface methodology (henceforth referred to as 'polynomial regression,' since response surface method also follows the same regression principals) in IS research is scant. To the best of our knowledge, only a small number of studies have even suggested the importance of polynomial regression and response surface method (see Brown et al. 2008; Roberts and Grover 2012b; Titah and Barki 2009). However, a review of the literature reveals that polynomial regression could have been applied in most of the IS studies to derive deeper and better theoretical explanations. For example, Appendix A includes a sample of 14 articles from the two leading journals in the discipline, MIS Quarterly and Information Systems Research, that could have employed polynomial regression to improve their insights. It is highlighted that the original intention of these studies was not to employ polynomial regression. For example, in the study of alternative sampling in digital age by Steelman et al. (2014), inclusion of polynomial regression could have complemented the traditional structural model testing, further elaborating (i) how different combinations of perceived usefulness and perceived ease of use impact the behavioural intention? and (ii) how combinations of perceived usefulness and perceived ease of use impact the behavioural intention across different cohorts of samples. Observing the new research questions, one might come to an invalid conclusion that the focus of polynomial regression is limited to observing the impact of two variables in combination on the dependent variable. In fact, the polynomial regression can assess the complete interaction effect of two variables on the dependent variable. This means, that the studies in Appendix A could have observed (i) the optimal combinations and (ii) the effect of variables on a continuum. As such, it can be argued that the IS researchers have missed opportunities to provide greater insights by not adhering to the notions of polynomial regression and response surface methodology. With the objective of providing the methodological awareness, the next section provides an overview of the method, its fundamental assumptions and details of how results are interpreted.

\section{Overview of polynomial regression and response surface methodology}

Polynomial regression is a technique that can be used to model the relationship between multiple independent variables ( $X$ and $Y$ ) in relation to a dependent variable $(Z)$ through a non-linear relationship (Shanock et al. 2010). Citing Edwards (1994), Venkatesh and Goyal (2010, p. 286) state "based on a basic theoretical model, $Z=f(X, Y)$, this technique allows the examination of curvilinear terms so that a more accurate picture of the relationship between component measures and an outcome variable can be detected."

Polynomial modelling involves a hierarchical analysis of polynomial equations, which continues until the variance explained by the next higher-order equation is not statistically significant. For example, a quadratic polynomial equation is

$Z=b_{0}+b_{1} X+b_{2} Y+b_{3} X^{2}+b_{4} X Y+b_{5} Y^{2}+e$

Here, component scores for $\mathrm{X}$ and $\mathrm{Y}$ (first stage $\mathrm{X} 1$ and $\mathrm{Y} 1$ ) are entered to test their linear relationship with $\mathrm{Z}$ in hierarchical stages. During the second stage of analysis, higher-order terms ( $\mathrm{X} 2$ and $\mathrm{Y} 2)$ are added into the equation along with the product term $(\mathrm{XY})$ to test for the presence of curvilinear (here, quadratic) relationships. Subsequently, cubic terms could be 
added into the equation in order to test for the presence of further higher-order curvatures (Edwards 2002; Edwards and Van Harrison 1993).

Similar to polynomial regression (Edwards and Parry 1993), response surface methodology (Box and Draper 1987; Khuri and Cornell 1987) is a common technique that analyse nonlinearities. Moreover, the polynomial regression, together with the response surface methodology, provides the basis for testing and interpreting the features of surfaces corresponding to polynomial quadratic regression equations. Especially, these techniques are popular in micro and macro organizational literature to investigate congruence and/or discrepancies between variables (Shanock et al. 2010). Moreover, polynomial modelling and response surface methodology have been used widely in organization behaviour (e.g., Hecht and Allen 2005; Kristof 1996), marketing (e.g., Kim and Hsieh 2003), and personnel psychology (e.g., Shaw and Gupta 2004).

These techniques allow a researcher to examine the extent to which the combinations of two predictor (independent) variables relate to an outcome (dependent) variable. Further, this has been widely used in multi-source feedback research (Shanock et al. 2010). The combination of the two methods provides the statistical insight required to examine the nuanced views of tripartite relationships by investigating the variables in a three-dimensional space where it provides the relationships between combinations of two predictor variables and an outcome variable (Shanock et al. 2010).

\subsection{Assumptions of polynomial regression}

Generally, the polynomial regression and response surface methodology can be used for any circumstances in which the phenomenon involves an investigation of how combinations of two predictor variables relate to an outcome. However, Edwards (2002) outlines few assumptions that must be met in order to apply this analytical technique. First, the two predictor variables must be commensurate and thus should represent the same conceptual domain. As such, the relationship between the predictor variables can be interpreted in a meaningful way in relation to the dependent variable. For an example, if a researcher is trying to predict a customer's satisfaction with the service provided in a hotel, it is more meaningful to look at customer satisfaction (Outcome Variable $\mathrm{Z}$ ) in relation to the discrepancy or agreement between the customer's expectations (Variable $X$ ) and the actual customer experience (Variable $\mathrm{Y}$ ).

Second, the predictor variables ( $\mathrm{X}$ and $\mathrm{Y}$ ) must be measured on the same numeric scale; or, when the scales are different, the scales should be transformed to a standardized scale so that the degree of correspondence between the variables can be determined in a more accurate manner. For example, both variables are required to be measured on a 5-point or 7-point Likert scale (e.g., "strongly disagree" to "strongly agree" / "not at all" to "very frequently"). In case the two scales are different (e.g., 7-point Likert and 5-point Likert scale), the scales need to be standardized to a single scale in order to place both variables on a common metric (See Harris et al. 2008).

Third, as with any regression technique, all the standard assumptions relating to the multiple regression technique as explained by Tabachnick and Fidell (2007) need to be met in order to apply this technique. Moreover, polynomial regression could be used in the place of moderated regression to study the relationships between combinations of variables ( $\mathrm{X}$ and $\mathrm{Y}$ ). The reason for this is that the polynomial regression has more explanatory power compared 
to the traditional moderated regression as it provides nuanced views on the relationships between different combinations of predictor variables (X and $Y$ ) and a dependent variable $(Z)$ in a three-dimensional space (Shanock et al. 2010).

Finally, the polynomial regression and response surface methodology can be used when the underlying theoretical assumptions suggest non-linearity between the independent and dependent variables. For example, the original theoretical assumptions of the ECT suggest non-linearities in the relationships between expectations, experience and satisfaction (Oliver 1977; Oliver 1980). Thus, studies that use ECT as the underlying theoretical lens could employ polynomial regression together with response surface methodology to establish nuanced views of the relationships between the three variables of expectation, experience and satisfaction (Brown et al. 2012; Brown et al. 2014; Brown et al. 2008). Once it has been ensured that the above assumptions are met then the polynomial regression needs to be run to resolve the polynomial equation and to obtain the outputs. Then, the polynomial outputs needs to be projected in a three-dimensional response surface as the higher order polynomial outputs often result from a polynomial model are difficult to interpret (Edwards 2001). Shanock et al. (2010) provides a detailed stepwise guidance for conducting polynomial regression and creating the response surface using polynomial outputs.

\subsection{Interpretation of the response surface}

The interpretation of the resultant response surface is accompanied by four properties (denoted using a1, a2, a3 and a4), that are relating to the slope and the curvature of response surface. The property a1 is related to the slope or the inclination of the surface along the agreement line $(X=Y)$ whereas the property a2 relates to the curvature of the $X=Y$ line. Similarly, the properties a3 and a4 relate to the slope and the curvature of the surface along the disagreement line $(\mathrm{X}=$ negative $\mathrm{Y})$ respectively. As such the four indicators a1, a2, a3 and a4 relate to the inclination and the curvature of the surface along the two perpendicular axes $\mathrm{X}=\mathrm{Y}$ and $\mathrm{X}=$ negative $\mathrm{Y}$.

Several different research questions can be answered through the resultant response surface and the calculated surface values. For example, using a response surface, a researcher can examine: (i) the agreement or alignment between two predictor variables on an outcome variable, (ii) the discrepancy between two predictor variables on an outcome variable, (iii) the direction and magnitude of the discrepancy between two predictor variables on an outcome variable, (iv) the nature of the synergy between two predictor variables (positive or negative) and outcome variable, and (v) the mediation effect of one predictor variable on the other predictor variable (complete or partial) on an outcome variable. It is noted that, while individually useful, the aforementioned five types of analyses must be viewed in combination, rather than in isolation. Moreover, as exemplified in Table 2, each line must be assessed together with its significance and not just on the shape or slope of the surface.

Panel A in Figure 1 provides the $\mathrm{X}, \mathrm{Y}$ and $\mathrm{Z}$ axes and lines of congruence and incongruence, while Panel B in Figure 1 includes a sample of a response surface graph using two predictor variables ( $\mathrm{X}$ and $\mathrm{Y}$ ) and one dependent variable $(\mathrm{Z})$. 

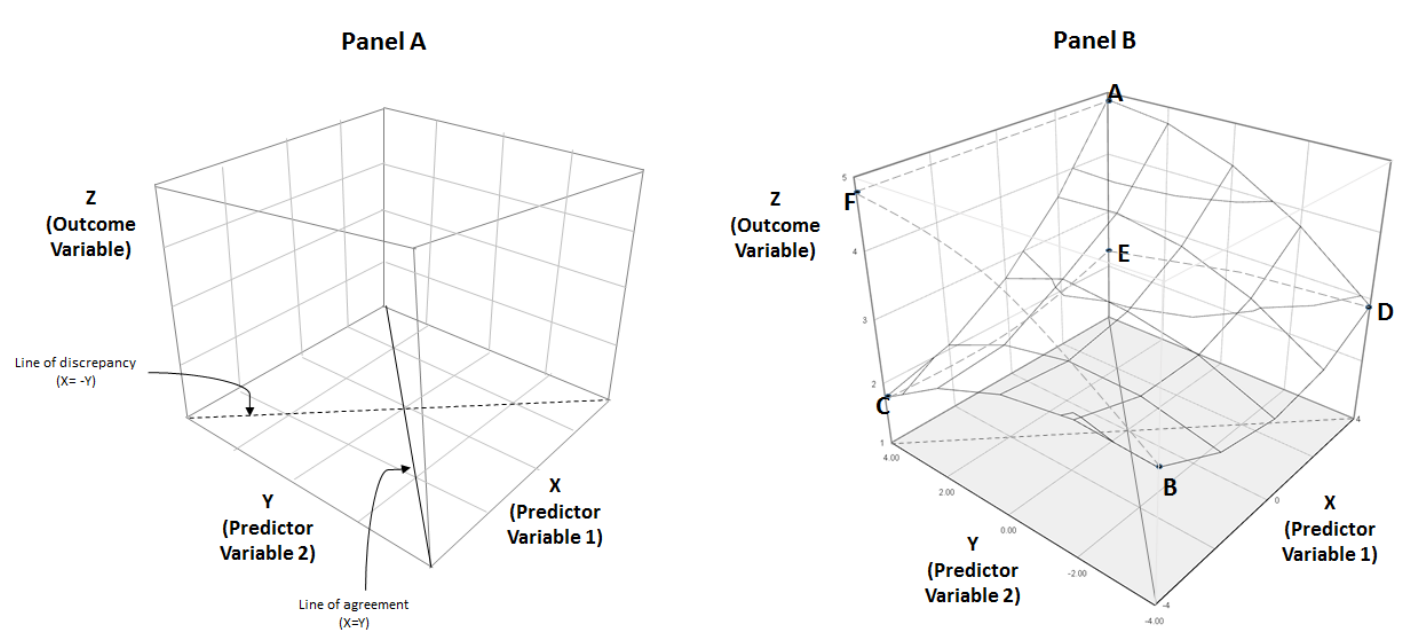

Figure 1. A sample graph for a response surface of two predictor variables ( $X$ and $Y$ ) and an outcome variable (Z)

\subsubsection{Agreement between two predictor variables as related to an outcome variable}

A key mechanism of the response surface methodology allows a researcher to study the agreement between two predictor variables in relation to an outcome variable. In panel $B$ of Figure 1, the line between point A and B of the surface area of the graph (marked as ABCD) depicts the perfect agreement or alignment between the two predictor variables (which means $\mathrm{X}$ is equal to $\mathrm{Y}$ ). Whilst the surface property a1 (slope or the inclination of the surface along agreement line, $\mathrm{X}$ is equal to $\mathrm{Y}$ ) explains the slope of the surface along $\mathrm{A}$ to $\mathrm{B}$ (i.e. the agreement line), a2 (curvature of the $X$ is equal to $Y$ ) explains the curvature or the non-linearity of the surface along the A-B line (Panel B). If the test value $\mathrm{a}_{1}$ is positive (negative), the outcome variable increases (decreases) as the two predictor variables increase. Whilst the significant value of a indicates a non-linear (curvilinear) slope along the agreement axis, a significant positive a value suggests an upward convex curvature for the surface along the A-B line, whilst a significant negative a2 value suggests a downward concave curvature for the surface along the A-B line. If the agreement between two predictor variables shows a linear additive relationship to the outcome variable $\mathrm{a}_{1}$, the slope is positive but if it shows a linear additive relationship to the outcome variable, thus a2, the curvature of the surface along the line of agreement would not be significant.

Moving along the solid line from the front of the graph in Panel B of Figure 1 (Point B) to the back (Point A), the line of perfect agreement of two predictor variables as related to outcome variable $(Z)$ has a positive slope. Further, the lowest level of the outcome variable is at the front corner of the graph on the A-B line (Point B) where both predictor variables are low, and increasingly higher towards the back corner of the graph on the A-B line (Point A) where both predictor variables are high.

\subsubsection{Disagreement between two predictor variables as related to an outcome variable}

Disagreement, or incongruence, explains how the discrepancy between two predictor variables relates to an outcome variable. The line perpendicular to the line of perfect agreement (the A-B line on the ABCD response surface) represents the line of incongruence. The dotted line on the floor of the graph in Panel B of Figure 1 depicts this line of incongruence $(\mathrm{X}=$ negative $\mathrm{Y})$, that is, when the two predictor variables are not in agreement. As the surface 
property a4 explains the curvature along the line $X=$ negative $Y$, a significant negative curvature depicts that the dependent variable drops as the difference between the two predictor variables widens (i.e. increasingly discrepant as moving away from the line of agreement). Whilst a significant negative a4 indicates a concave surface, a significant positive a4 indicates a convex surface. The concave surface explains that the value of the outcome variable decreases more sharply as the degree of discrepancy between the two predictor variables increases; whilst the concave surface explains vice versa. The surface along the line of disagreement of the graph in Panel B of Figure 1 displays a concave surface and shows a sharp decrease in the outcome variable as the discrepancy between the predictor variables widens.

\subsubsection{Direction and magnitude of the discrepancy between two predictor variables as related to an outcome variable}

The slope along the line of incongruence between the two predictor variables ( $\mathrm{X}=$ negative $\mathrm{Y}$ ) as related to the dependent variable explaining the extent to which the direction of the discrepancy matters to the outcome variable. As the surface property az relates to the slope of the line of incongruence as it relates to the outcome variable, a significant value for az shows that the direction of discrepancy indeed matters to the changes in the outcome variable. A significant positive аз indicates that the outcome variable decreases when predictor variable 1 $(\mathrm{X})$ is less than predictor variable $2(\mathrm{Y})$ and vice versa.

Moreover, the graph in Panel B of Figure 1 shows that moving to left or right of the agreement line' on the floor (i.e. towards points $X$ and $D$ of the $A B C D$ response surface on the graph respectively), where the two predictor variables become more and more discrepant one could observe the changes in the outcome variable as a result of the discrepancies between predictor (X and $Y$ ) variables. Such observations will be evident through the slope (as) and curvature (a4) of the surface along $C$ and D. Moving away from the agreement line towards point $C$ along the horizontal dotted line on the floor of the graph, the predictor variable 2 (Y) increases and predictor variable $1(X)$ decreases and the outcome variable $Z$ decreases. Similarly, moving from the agreement line towards point $\mathrm{D}$ along the dotted line on the floor of the graph, the predictor variable $1(\mathrm{X})$ increases as predictor variable $2(\mathrm{Y})$ decreases. This highlights the observations that can be made on the discrepancy and direction of assimilation between two predictor variables using the resultant response surface.

\subsubsection{Synergy between two predictor variables as related to an outcome variable}

Synergy between two predictor variables has been described as the combined effect of two factors $(X$ and $Y)$, where the combined effect could either create a negative synergy (making the combined effect of the two factors less than the sum of each factor's separate effect) or a positive synergy (making the combined effect of the two factors greater than the sum of each factor's separate effect) (Titah and Barki 2009). Positive synergy explains the complementarity of two variables, whereby it explains that the increase in either factor increases the impact of the other (Titah and Barki 2009). Similarly, negative synergy explains the substitutability of two variables, whereby it explains that the increase in one factor decreases the impact of the other.

The lines of $A$ to $C$ and $B$ to $D$ of the $A B C D$ surface provide an example of positive synergy. The B-D line represents the relationship between predictor variable 1 and the outcome variable when predictor variable 2 is at its lowest. The A-C line represents the relationship between predictor variable 1 and the outcome variable when predictor variable 2 is at its highest. Both 
lines show that the outcome variable increases with the increase of predictor variable 1 (Points $\mathrm{C}$ to $\mathrm{A}$ and $\mathrm{B}$ to $\mathrm{D}$ ). However, the rate of increase (i.e. slope of the curve) is higher in the C-A curve compared to the C-D curve. The in-between line on the response surface that runs parallel to the two A-C and B-D curves also shows that the slope of the curve increases when moving from the B-D line towards the A-C line. This shows that, as predictor variable 1 increases, it positively influences the relationship between predictor variable 1 and the outcome variable $Z$, suggesting a positive synergy between the two predictor variables.

Alternatively, the E-C and BD lines of the ECBD response surfaces provide an example of negative synergy. The B-D line represents the relationship between predictor variable 1 and the outcome variable when predictor variable 2 is at its lowest. The E-C line represents a hypothetical relationship between predictor variable 1 and the outcome variable when predictor variable 2 is at its highest. Both lines show that the outcome variable increases with the increase of predictor variable 1 (Points $C$ to $E$ and $B$ to D). However, the rate of increase (i.e. the slope of the curve) is less in the C-E curve compared to the C-D curve. Similar to the earlier example, if lines were to be drawn on the hypothetical ECBD response surface, hypothetical lines that runs parallel to the E-C and B-D lines, it would show that the slope of the curve decreases moving from the B-D line towards the E-C line. This shows that, as predictor variable 1 increases, it negatively influences the relationship between predictor variable 1 and the outcome variable $\mathrm{Z}$ and suggests a negative synergy between the two predictor variables.

\subsubsection{Test of Mediation}

Mediation in general entails the intervening effect of an antecedent variable on a dependent variable. Thus, mediation refers to the intervening effect of one of the predictor variables on the relationship between the other predictor variable and the outcome variable. The discussion herein focuses on the mediation of predictor variable $Y(2)$ on the relationship between predictor variable $X(1)$ and the outcome variable $Z$. Two types of mediation, namely, partial mediation and complete mediation, are discussed in the literature (see Roberts and Grover 2012a). To discuss the two types of mediation, this section uses the two response surfaces $\mathrm{ABCD}$ and $\mathrm{ABDF}$ - of the graph in Panel B of Figure 1. However, the argument of mediation or moderation effect of a variable must be carefully made only through a theoretical grounding - rather than using polynomial equations as a tool of exploration. Venkatesh and Goyal (2010) highlight that advances in moderation and mediation (e.g., Edwards and Lambert 2007) have allowed researchers to incorporate the effects of moderators and mediators into polynomial models in organizational behaviour.

We take the $A B C D$ response surface of the graph to discuss partial mediation. Both A-C and B-D lines (or curves) of the graph explain the relationship between predictor variable $X$ and the outcome variable $Z$. The B-D line of the graph explains the relationship between predictor variable $X$ and the outcome variable $Z$ when predictor variable $X$ is absent or at its lowest, whilst the A-C line explains the relationship between predictor variable $X$ and the outcome variable $Z$ when predictor variable $X$ is at its highest. Both the $A-C$ and $B-D$ lines in the graph show that as predictor variable $X$ increases, the outcome variable $Z$ also increases as a result. When moving from the B-D line towards the A-C line on the response surface, it shows that when the magnitude of the predictor variable $\mathrm{Y}$ increases, the relationship between predictor variable $X$ and the outcome variable $Z$ (i.e. the slope or curvature between predictor variable $X$ and the outcome variable $Z$ changes) changes slightly. It means that predictor variable $Y$ 
mediates the relationship between predictor variable $\mathrm{X}$ and the outcome variable $\mathrm{Z}$, but the impact of the predictor variable $\mathrm{Y}$ is only partial.

Next, we take the ABDF response surface of the graph to discuss complete mediation. Similar to the above discussion, both the $\mathrm{AF}$ and $\mathrm{BD}$ lines (or curves) of the graph explain the relationship between predictor variable $X$ and the outcome variable $Z$. Whilst the B-D line of the graph explains the relationship between predictor variable $X$ and the outcome variable $Z$ when predictor variable $\mathrm{Y}$ is absent or at its lowest, the F-A line explains the relationship between predictor variable $\mathrm{X}$ and the outcome variable $\mathrm{Z}$ when predictor variable $\mathrm{Y}$ reaches its highest. Whilst the B-D line shows that, as predictor variable $X$ increases, the outcome variable $\mathrm{Z}$ also increases consequently, the $\mathrm{F}$-A line shows no change to the outcome variable as predictor variable $\mathrm{X}$ increases when predictor variable $\mathrm{Y}$ is at its highest. When moving from the B-D line towards the F-A line on the response surface, it shows that when predictor variable $\mathrm{Y}$ increases, the relationship between predictor variable $\mathrm{X}$ and the outcome variable $Z$ changes substantially. This explains that predictor variable $Y$ acts as a strong mediator in the relationship between predictor variable $\mathrm{X}$ and the outcome variable $\mathrm{Z}$.

\section{Applying polynomial regression to a study of ECT}

Having demonstrated the methodological approach of polynomial regression and response surface, the following section of the paper uses primary data collected by the authors to demonstrate the theoretical and practical applications of polynomial regression and surface response method.

Expectation confirmation theory (ECT - also known as the Expectation disconfirmation theory) is an ideal theoretical example to demonstrate the strengths of the polynomial regression and surface response method. The measurement of confirmation in ECT involves comparing two distinct component measures: pre-exposure expectation and post-exposure experience (Venkatesh and Goyal 2010). Therein, instead of testing the linear model, the method allows us to determine the difference in the absolute level of confirmation, when the values of both expectations and experiences are high (rather than when both are low, a distinction that is not possible to assess using direct measures) (Venkatesh and Goyal 2010).

To test the ECT purported relationships between expectations, experience and customer satisfaction, we gathered data from 171 Australian consumers prior to their retail experience using a retail mobile app (with a response rate of $40 \%$ ). Prior to analysis, we conducted a wave analysis (Armstrong and Overton 1977) to assess the impact of non-respondent bias, whereby the respondents were grouped into early and late respondents and online and offline respondents and comparisons were made according to the respondents' age (under 21 years $=$ $19 \%, 22-32=37 \%, 33-43=27 \%, 44-55=11 \%$, over $56=6 \%$ ) and gender ( $46 \%$ male, $54 \%$ female). Our analysis revealed no significant differences between early and late respondents or between the other combinations. Based on our findings, non-response bias does not appear to impact on our study. Moreover, the assessment of outliers of the sample found no abnormalities. In the linear model, the theoretical constructs of 'expectation' and 'experience' explained $63 \%$ of the variance in the dependent variable - 'satisfaction' $\left(\mathrm{r}^{2}=0.63\right)$. The beta value of path between expectation and satisfaction was 0.002 significant at 0.5 , while the beta of the path between experience and satisfaction was 0.645 , significant at 0.001 . 


\subsection{Theorizing for polynomial regression and response surface methodology}

Considering the analytical potential of the polynomial regression (and response surface methodology) guidelines on theorizing tri-partite relationships for various research questions that have been discussed earlier would be of great value. Theorizing a tri-partite interaction effect between two predictor variables with an outcome variable in a three-dimensional space and developing testable hypotheses is a challenging task. As such, the section below provides a practical guideline for theorizing the five views of the three variables taking ECT (Oliver 1977; Oliver 1980) as an example.

\subsubsection{Agreement between two predictor variables as related to an outcome variable}

As the two predictor variables represent the two axes of $X$ and $Y$, the agreement between two predictor variables corresponds to the line representing $\mathrm{X}$ equals to $\mathrm{Y}$ coordinates. Thus, the agreement between two predictor variables and their relationships with the outcome variable corresponds to the response surface along the $X$ equals to $Y$ axis. In other words, how the outcome variable is influenced by the alignment between two predictor variables when both variables are at their lowest to the highest is evident in the behaviour of the response surface corresponding to the $\mathrm{X}$ equal to $\mathrm{Y}$ line.

In the case of the example using ECT, this paper examines the tri-partite relationship between expectation, experience and satisfaction. Expectation and experience are the two predictor variables, while satisfaction is the outcome variable. Also, observations suggest that it is more likely that one reaches a high level of satisfaction when high expectations are met with matching high experiences as compared with the level of satisfaction derived as a result of matching low expectations with low experience. Whilst ECT suggests the customer expectations need to be matched to satisfy the customers; it can be argued that, the alignment between customer expectations and their actual experience is positively related to customer satisfaction.

\subsubsection{Disagreement between two predictor variables as related to an outcome variable}

Disagreement refers to the mismatch or the misalignment. Thus, in the context of our discussion the term misalignment refers to the incongruity between the two predictor variables. As the alignment line represents the $X=Y$ coordinates, the misalignment refers to the line perpendicular to line of alignment, which is $X=$ negative $Y$ line. As the $Z$ axis represents the outcome variable satisfaction, the surface corresponds to the $X=$ negative $Y$ line and denotes how the misalignment between two predictor variables (in our case it is expectation and experience) relates to the satisfaction. Also, the interception between $X=Y$ line and $X=$ negative $Y$ depicts the point in which the two predictor variables having minimal mismatch, where moving away from the interception of the two lines to either direction (the left or right) shows the degree of discrepancy (mismatch) between the two predictor variables.

Herein the conceptual challenge is to make theoretical predictions about the mismatch between two predictor variables and its relationship to the outcome variable in a threedimensional space. In the example provided, as conceived in ECT, expectations and experiences need to be matched for satisfaction and a mismatch between the two could create dissatisfaction. Hence, it can be argued that, the incongruence between customer expectations and their experience is negatively related to customer satisfaction. 


\subsubsection{Direction of discrepancy between two predictor variables as related to an outcome variable}

Another important consideration is the direction of the discrepancy between the two predictor variables and its effect on the outcome variable. Conceiving this could be even more challenging as one should consider the individual relationships between the two predictor variables against the outcome variable in relation to the mismatch and the outcome. The inclination of the surface depends upon the nature of the relationship between individual predictor variable and the outcome variable.

As discussed earlier, the response surface corresponding to the intersection between the agreement and disagreement lines provides a reference point to discuss the variations in outcome variable as it relates to the direction of discrepancy between the two predictor variables (moving towards either direction from that intersection).

In the example, the aforementioned point shows the level of satisfaction in point which the two lines expectations-experience agreement and the expectation-experience disagreement intersect. Moving towards experience dimension (the axis that denotes experience) from that intersection on the line of incongruence, the discrepancy assimilates towards experience (experience > expectations); and when moving towards the expectations dimension (towards other side, towards experience axis in which expectation > experience) from the intersection, the discrepancy assimilates towards expectations. The conceptual challenge here is to predict the outcome variable when moving either side of the intersection that we have mentioned earlier, hence one should carefully consider the one-on-one relationships between expectations and experience (independent variables) and satisfaction (the outcome variable) and the interaction effect between expectations and experience.

\subsubsection{Synergy between two predictor variables as related to an outcome variable}

Synergy refers to the combined effect of two factors. Thus, synergy is discussed here in relation to the combined effect of the two predictor variables on the outcome variable. As such, when theorizing the relationship, one should consider the relationship between the two predictor variables with the outcome variable, when one predictor variable is absent and until that variable reaches its maximum. The line where the value of $X$ axis (or $Y$ axis) is at its minimum is the point which the predictor variable that represents $X$ axis (or $Y$ axis) is at its minimum. The line where the value of $X$ axis (or $Y$ axis) is at its maximum is the point which the predictor variable that represents $\mathrm{X}$ axis (or $\mathrm{Y}$ axis) is at its maximum. The changes of the inclination of the surface corresponding to the line where the value of $X$ axis (or $Y$ axis) is minimum and the line where the value of $X$ axis (or $Y$ axis) is maximum (and the parallel lines in between) explain the type of synergy (whether that is positive or negative) between the two predictor variables.

In the ECT example, a synergistic relationship can exist between expectations and experience and their effect on the outcome variable, satisfaction. Thus, to explain the relationship, the relationship between expectations and satisfaction when the experience is at its lowest was taken into consideration. Next, the relationship between expectations and satisfaction when the experience is at its highest (and the lines parallel and in between the two lines) was taken into account. Based on the observations, theoretical arguments of the earlier conceptions of the theory and the assumptions, a positive synergy between the two predictor variables in generating customer satisfaction was identified. 


\subsubsection{Testing the Mediation Effect of Predictor Variable 2 on the Relationship between Predictor Variable 1 and an Outcome Variable}

Mediation entails the intervening effect of an antecedent variable (Predictor Variable X) on an outcome variable. Herein, the theorizing of the mediation effect could be done for two types of mediations - partial and complete. The mediation effect is partial, when the presence of mediation variable increases the relationship between predictor variable $X$ and the outcome variable $\mathrm{Z}$ alters partially / gradually. Conversely, the mediation effect is complete when the relationship between predictor variable $X$ and outcome variable $Z$ changes completely when the mediator is added to relationship.

In the case of ECT, the focus is on the mediation effect of experience on the relationship between expectations and satisfaction. As expectations increase, it is more likely that it has a negative relationship to satisfaction (since the expectations serves as the base line for evaluating experiences to form satisfaction). However, it is more likely that in the presence of experience, the relationship between expectations and satisfaction alters as experience is mediating the original relationship. It is more likely that experience makes substantial changes to the relationship between expectations and satisfaction. Thus, it can be argued that the mediation effect of experience on expectation-satisfaction relationship is complete.

\subsection{Generating the polynomial outcomes and the response surfaces}

In a study that the authors conducted, the ECT was employed to investigate the tripartite relationship between customer expectations, customer experience and customer satisfaction in the context of customers' use of smart shopping apps in consumer retail. Therein, it was argued that customer satisfaction is defined by expectations and actual experience, and where the level of satisfaction is determined by the degree to which the prior expectations are confirmed by the actual experience (Oliver 1977; Oliver 1980). Therefore, the differences between expectations and experience are considered important for achieving satisfaction. In this example, customer expectations and customer experience are the two predictor variables, and customer satisfaction is the outcome variable. As such, customer expectations variable was identified as $\mathrm{X}$ variable, customer experience as the $\mathrm{Y}$ variable, whilst customer satisfaction is labelled as the outcome variable $\mathrm{Z}$.

The following polynomial equation was employed to test the tripartite relationship between customer expectations, customer experience and customer satisfaction:

Customer Satisfaction $=f\left(\right.$ Customer Expectations $*$, Customer Experience $\left.{ }^{* *}\right)$

$Z=\beta_{0}+\beta_{1} \operatorname{CExpt}^{*}+\beta_{2} \operatorname{CExpr}^{* *}+\beta_{3} \operatorname{CExpt}^{2}+\beta_{4}(\operatorname{CExpt} \times \operatorname{CExpr})+\beta_{5} \operatorname{CExpr}^{2}+\mathrm{e}$

Where, ${ }^{*} \mathrm{CExpt}=$ Customer Expectations, and ${ }^{* *} \mathrm{CExpr}=$ Customer Experience

The procedure outlined in Shanock et al. (2010) was followed to run the polynomial regression analysis on the data collected from 428 respondents in a field study and to create the response surface for customer expectations, customer experience and customer satisfaction, as shown in Figure 2. Table 1 provides the output coefficients of polynomial regression by employing syntax similar to the Table 2 in Appendix 2 in Shanock et al. (2010). Table 2 in Shanock et al. (2010) provides the four surface properties, a1, a2, a3 and a4, calculated using the Microsoft Excel worksheet. The test value a1 corresponds to the slope of the surface alone the line of perfect agreement between two predictor variables $\left(\mathrm{PV}_{1}=\mathrm{PV}_{2}\right.$ or $\left.\mathrm{X}=\mathrm{Y}\right)$ where it is related to the dependent variable $Z$. Where $a_{1}=\left(b_{1}+b_{2}\right)$, and $b_{1}$ and $b_{2}$ are the non-standardized beta coefficients for the scale centred $\mathrm{PV}_{1}$ and $\mathrm{PV}_{2}(\mathrm{X}$ and $\mathrm{Y})$, respectively. Meanwhile the test value 
a2 corresponds to the curvature along the line of perfect agreement between two predictor variables $\left(\mathrm{PV}_{1}=\mathrm{PV}_{2}\right.$ or $\left.\mathrm{X}=\mathrm{Y}\right)$ as related to the dependent variable $\mathrm{Z}$. It is given by $\mathrm{a}_{2}=\left(\mathrm{b}_{3}+\mathrm{b}_{4}+\mathrm{b}_{5}\right)$, where $b_{3}, b_{4}$ and $b_{5}$ are the non-standardized beta coefficients for the scale-centred $D_{1}$ squared $\left(X^{2}\right)$, cross-product $\left(\mathrm{DV}_{1}{ }^{*} \mathrm{DV}_{2}\right.$ or $\left.\mathrm{XY}\right)$ and $\mathrm{DV}_{2}$ squared $\left(\mathrm{Y}^{2}\right)$, respectively to incorporate nonlinearity. Similarly, the test value az corresponds to the slope of the line of incongruence between two predictor variables $\left(\mathrm{PV}_{1}=\right.$ negative $\mathrm{PV}_{2}$ or $\mathrm{X}=$ negative $\left.\mathrm{Y}\right)$ as related to the dependent variable $Z$. The value $a_{3}=\left(b_{1}-b_{2}\right)$, where $b_{1}$ and $b_{2}$ are the non-standardized beta coefficients for the scale-centred $\mathrm{PV}_{1}$ and $\mathrm{PV}_{2}$, respectively. This line explains the changes in DV $(Z)$ as related to the direction and magnitude of the discrepancy between two predictor variables $\left(\mathrm{IV}_{1}\right.$ is higher than / lower than $\left.\mathrm{IV}_{2}\right)$. Alternatively, the test value a4 corresponds to the curvature along the line of disagreement between two predictor variables ( $\mathrm{PV}_{1}=$ negative $\mathrm{PV}_{2}$ or $\mathrm{X}=$ negative $\left.\mathrm{Y}\right)$ as related to the dependent variable $\mathrm{Z}$. It is given by $\mathrm{a}_{4}=\left(\mathrm{b}_{3}-\mathrm{b}_{4}+\mathrm{b}_{5}\right)$, where $b_{3}, b_{4}$ and $b_{5}$ are the non-standardized beta coefficients for the scale-centred DV1 squared $\left(X^{2}\right)$, cross-product $\left(\mathrm{DV}_{1}{ }^{*} \mathrm{DV} \mathrm{V}_{2}\right.$ or $\left.\mathrm{XY}\right)$ and $\mathrm{DV}_{2}$ squared $\left(\mathrm{Y}^{2}\right)$, respectively. As such it is possible for $\mathrm{a}_{1}, \mathrm{a}_{2}, \mathrm{a}_{3}$ and $\mathrm{a}_{4}$ to be independently be significant or non-significant as they are related to the two different properties of the two different lines of the resultant response surface.

Next, the response surface for agreement, discrepancy, direction of discrepancy, synergy and mediation effects was tested, and the results are as follows.

\begin{tabular}{|l|c|}
\hline \multicolumn{1}{|c|}{ Variable } & Beta coefficient / non-standardized regression coefficients \\
\hline Intercept $/$ constant $\left(\beta_{0}\right)$ & 4.693 \\
\hline Expt $=$ Customer expectations $(X)$ & $0.055^{*}$ \\
\hline Expr $=$ Customer experience $(\mathrm{Y})$ & $0.533^{* *}$ \\
\hline $\operatorname{Expt}^{2}\left(\mathrm{X}^{2}\right)$ & -0.033 \\
\hline $\left.\operatorname{Expt}^{*} \operatorname{Expr}^{2} \mathrm{XY}\right)$ & 0.018 \\
\hline $\operatorname{Expr}^{2}\left(\mathrm{Y}^{2}\right)$ & 0.046 \\
\hline \multicolumn{2}{|c|}{} \\
\hline
\end{tabular}

Table 1. Results of polynomial equation involving Customer Expectations, Customer Experience and Customer Satisfaction

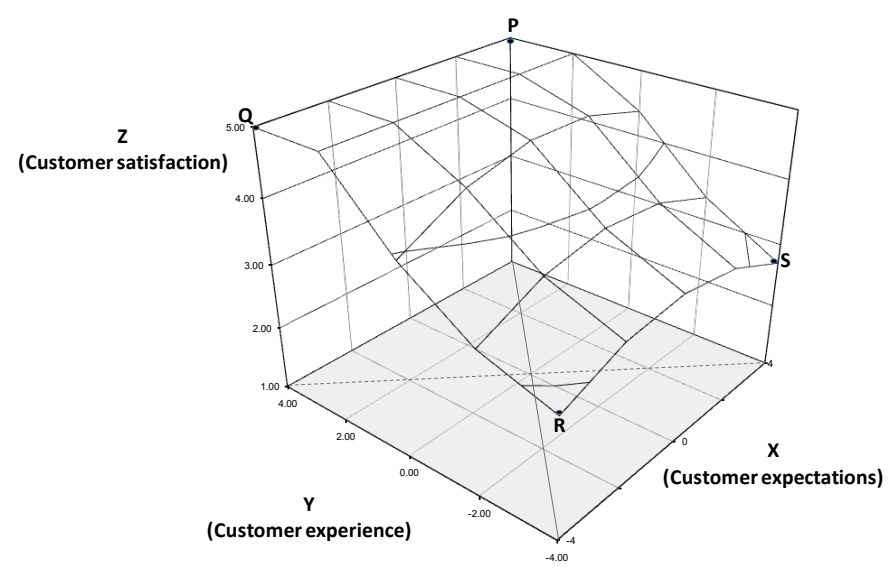

Figure 2. Response surface for two predictor variables - Customer Expectations (X), Customer Experience (Y) and Customer Satisfaction ( $Z$ ) 


\begin{tabular}{|c|c|c|c|c|c|}
\hline Effect & Coefficient & Standard error & Test stat (t) & P value & Significance \\
\hline $\begin{array}{c}\text { a1: Slope along } X=Y \text { (as related } \\
\text { to Z) }\end{array}$ & 0.59 & 0.11 & 5.507 & 0.000 & Significant \\
\hline $\begin{array}{c}\text { a2: Curvature on } X=Y \text { (as } \\
\text { related to } Z \text { ) }\end{array}$ & 0.03 & 0.03 & 1.186 & 0.236 & Non-significant \\
\hline $\begin{array}{c}\text { a3: Slope along } X=-Y \text { (as related } \\
\text { to Z) }\end{array}$ & -0.48 & 0.03 & -14.286 & 0.000 & Significant \\
\hline $\begin{array}{c}\text { a4: Curvature on } X=-Y \text { (as } \\
\text { related to } Z)\end{array}$ & 0.00 & 0.04 & -0.119 & 0.905 & Non-significant \\
\hline
\end{tabular}

Table 2. Properties of the response surface between Customer Expectations, Customer Experience and Customer Satisfaction

\subsection{Interpreting the response surfaces for five different research questions}

\subsubsection{Agreement between Customer Expectations and Customer Experience as related to Customer Satisfaction}

The solid line on the floor of the graph represents the line $\mathrm{P}$ to $\mathrm{R}$ on the three-dimensional surface of Figure 2, where it depicts the perfect agreement between the two predictor variables, customer expectations and customer experience (i.e. $\mathrm{X}=\mathrm{Y}$ ). As suggested in ECT, the customer expectations need to be matched to satisfy the customers. Thus, the alignment between customer expectations and their actual experience is positively related to customer satisfaction where the line of alignment $(X=Y)$ has a positive slope through the line from $\mathrm{R}$ to $\mathrm{P}$. Hence, the agreement between the customers' expectations arising from their use of smart shopping apps and the customers' ultimate shopping experience matters to the customers' final satisfaction. The level of customer satisfaction is lowest at the front corner of the graph along the line of agreement where customers' expectations as well as customer experience both stay low. Respectively, the satisfaction becomes increasingly higher towards the back of the graph as customer expectation and experience both reach higher levels. As seen in Table 2, only the slope along the P-R line is significant (a1), but the curvature along the P-R line remains nonsignificant.

\subsubsection{Discrepancy between Customer Expectations and Customer Experience as related to Customer Satisfaction}

The line perpendicular to the solid line of agreement $(X=Y)$ on the floor of the graph depicts the line of disagreement. In contrast, the dashed disagreement line on the floor of the graph in Figure 2 depicts the line of incongruence (the $X$ and $Y$ variables are not in agreement, i.e. $X=$ negative $Y$ ) and it represents the surface along the line $Q$ to $S$. Moving away from the interception of the two lines to either direction (the left or right) shows the degree of discrepancy (mismatch) between customer expectations and customer experience and how they relate to customer satisfaction. As conceptualized in ECT, customer expectations need to be matched for customer satisfaction; thus, the mismatch between customers' expectations and customers' actual experience could create customer dissatisfaction. The graph in Figure 2 shows that customers become satisfied when the difference between expectations and actual experience is at its lowest or when the actual experience exceeds their initial expectations. As presented in Table 2, the slope along the line of incongruence (Q-S) is significant (a1), whilst the curvature along the Q-S line remains non-significant. 


\subsubsection{Direction of discrepancy between Customer Expectations and Customer Experience as related to Customer Satisfaction}

As discussed earlier, the slope along the line of incongruence explains the extent to which the direction of discrepancy between the two predictor variables matters to the outcome variable. Whilst the point on the response surface corresponding to the intersection between the solid P-R and dotted Q-S lines on the floor of Figure 2 depicts the point of perfect agreement on the Q-S line, moving towards either direction from that intersection explains the incongruence. Moving towards Point $Q$ from the intersection, the discrepancy assimilates towards customer experience; moving towards Point $S$ from the intersection, the discrepancy assimilates towards customer expectations. Whilst the surface property az relates to the slope of the line of incongruence as it relates to the outcome variable, a significant value for a3 shows that the direction of discrepancy indeed matters to the changes in the outcome variable, and the test of the slope in Figure 3 indeed provides a significant value for аз as seen in Table 2. A significant negative a3 therein indicates that the customer satisfaction outcome variable increases when the discrepancy between customer expectations $(X)$ and customer experience $(Y)$ assimilates towards customer experience.

\subsubsection{Synergy between Customer Expectations and Customer Experience as related to Customer Satisfaction}

Synergy refers to the combined effect of two factors; thus, synergy is discussed here in relation to the combined effect of customer expectations and customer experience on customer satisfaction. The P-Q and R-S lines of the graph in Figure 2 show a positive synergistic relationship between customer expectations and customer experience. The R-S line shows the relationship between customer expectations and customer satisfaction when customer experience is absent or at its lowest. The P-Q line represents the relationship between customer expectations and customer satisfaction when customer satisfaction reaches its maximum. The lines running parallel to the P-Q and R-S lines on the surface show that customer satisfaction increases with the increase of customer expectations (moving from Points $R$ to $Q$ and $S$ to $P$ ). Whilst the R-S line shows a decrease in customer satisfaction as it reaches higher customer expectations, the decrease of customer satisfaction corresponds to higher levels of customer expectations diminishes in the lines that are parallel to R-S but are run closer to the P-Q line (lines that correspond to higher levels of customer experience). In addition, the slope of the curves that are parallel to the R-S line changes as customer experience increases, the slope of the lines diminishes, and customer satisfaction remains high as customer experience reaches its maximum levels. This shows that, as customer experience increases, it has a positive influence on the relationship between customer expectations and customer satisfaction, suggesting a positive synergy between the two predictor variables.

\subsubsection{Testing the mediation effect of Customer Experience on the relationship between Customer Expectations and Customer Satisfaction}

As mediation entails the intervening effect of an antecedent variable on a dependent variable, herein the focus is on the mediation of customer experience on the relationship between customer expectations and customer satisfaction. Next, reference is made to the graph in Figure 2 to test the mediation effect discussed above. The P-Q and R-S lines (or curves) of the graph therein explain the relationship between customer expectations and customer satisfaction. The R-S line explains the relationship between customer expectations and customer satisfaction when customer experience is absent or at its lowest. The P-Q line explains the relationship between customer expectations and customer satisfaction when 
customer experience reaches its highest. Meanwhile, the R-S line shows that when customer expectations reaches its highest, customer satisfaction decreases consequently, but the P-Q line shows no change to the outcome variable as the customer expectations increases from Point $Q$ to P. Further, a comparison of the R-S and P-Q lines shows that, as customer experience increases, the original behaviour of the relationship between customer expectations and customer satisfaction is disturbed completely. This explains that customer experience completely mediates the relationship between customer expectations and customer satisfaction, by impacting the relationship completely.

\section{Conclusion}

This paper outlined the basic assumptions under which the polynomial regression can be performed and the response surface methodology can be used in an analysis. It also outlined the theorizing of procedures for developing hypotheses on different research questions and provided detailed step-by-step guidelines on conducting the analysis and creating response surfaces. Next, the paper elaborated different research questions that can be investigated using this technique with the help of a hypothetical response surface for better comprehension of the technique and the interpretation of its results. Further, the paper provided a field-based example of the application of the methodology and the interpretation of findings to better comprehend the technique. In the process, several advantages of the polynomial regression and response surface methodology were identified. The polynomial regression and response surface methodology is a solution for the problems associated with the use of absolute, algebraic or squared differences between two scores (difference scores) in analysing discrepancies (Brown et al. 2008; Edwards 1994; Edwards 2002; Shanock et al. 2010). The polynomial regression has a clear advantage over the traditional use of differential scores in analysing incongruence in rating scales as it addresses the confounding effect associated with the traditional differential scores (Brown et al. 2008). For example, traditional difference scores confound the effects of two variables on the outcome by combining distinct measures into a single score. As such, the use of difference scores wouldn't allow a researcher to investigate the extent to which the measure of each component contributes to the outcome variable. Nor does it inform the researcher about which variable of the two is better for the outcome variable or vice versa. By using two component measures, polynomial regression can investigate the independent effects of the two variables on the outcome variable. Thus, the method keeps the independent effect of each component's measure intact. This enables a researcher to investigate the individual effects of each component measure on the outcome variable, the effects of the two component measures in combination on the outcome variable, and the effects of two component measures in different combinations/proportions on the outcome variable.

The second issue related to using difference scores is that it reduces the model dimensions to two from three-dimensions. Thus, the congruence between the two compound variables is denoted by a 'point' instead of showing it as a line (line of agreement $(X=Y)$, A-B line in Figure 2) which hides information that is valuable for clear interpretation and limits the explanatory potential. Further, the traditional regression analysis only provides a two-way interaction in a two-dimensional view compared to the three-dimensional view provided by the response surface methodology discussed herein. The polynomial regression together with response surface methodology facilitate a three-dimensional examination of the tripartite relationship between two predictor variables and an outcome variable, and thus improves the explanatory potential. The traditional model testing often carried out by IS researchers only provides a 
snapshot view of the data (e.g., the structural model tests in PLS and LISREL) and hence only provides information relating to the snapshot view and limits the nuanced views that the data could generate. For example, such structural models only provide a generalised relationship between variables taking the dataset but cannot provide information on how such relationships behave for the respondents who are at different levels of the measurement scale (unless the analysis is repeated using polarised samples). However, the three-dimensional response surface created in the polynomial regression and response surface methodology has the potential to provide nuanced views of the data in several different combinations. For example, in the response surface presented in Figure 2, moving along the line of agreement, a researcher can interpret how the outcome variable behaves when the value of perfect agreement is low, moderate or high (regarding any point that the researcher wishes to investigate). In addition, with this technique a researcher can investigate how the outcome variable behaves when the discrepancy between two variables is inclined towards either variable (for combinations with different proportions - along the $X=$ negative $Y$ line). Further, the traditional methods assume linearities between the variables even when the underlying theories suggest non-linearities. This could possibly mask the true explanatory potential of the model and may lead to misleading interpretations. However, by relaxing the linearity assumption, the polynomial regression with response surface methodology allows a researcher to investigate possible non-linearities between the variables by staying true to the original theoretical assumptions. In addition, by employing the response surface technique, a researcher could test for the significance of such non-linearities with response surface statistics a2 and a4. Further, the three-dimensional visualisations of the interactions among the three variables could provide nuanced views on the relationships when applied for comparison purposes (for two different samples, different time frames, different types of respondents etc.). This paper extends the works of Shanock et al. (2010) by elaborating on the structured guidelines to perform polynomial regression and response surface methodology to investigate alignment, discrepancy and the direction of discrepancy between two predictor variables and an outcome variable. Moreover, advantages of employing such an approach for making deeper and insightful research are highlighted by demonstrating possible research questions that could have been discussed in a sample of past IS studies.

The method has a major issue that researchers must be aware of. The method is susceptible to the presence of outliers, where one or two outliers in the data can seriously affect the results of the nonlinear analysis. As such, prior to analysis, the researcher must engage in removing the outliers. However, there are only fewer model validation tools for the detection of outliers in nonlinear regression than there are for linear regression.

\section{References}

Ajzen, I. 1991. "The Theory of Planned Behaviour," Organizational Behavior and Human Decision Processes (50:2), pp 179-211.

Ajzen, I., and Fishbein, M. 1980. Understanding Attitudes and Predicting Social Behaviour. Englewood Cliffs, NJ: Prentice Hall.

Armstrong, J.S., and Overton, T.S. 1977. "Estimating Nonresponse Bias in Mail Surveys," Journal of Marketing Research (14:3), pp 396-402. 
Balaji, S., and Brown, C.V. 2014. "Lateral Coordination Mechanisms and the Moderating Role of Arrangement Characteristics in Information Systems Development Outsourcing," Information Systems Research (25:4), pp 747-760.

Box, G.E.P., and Draper, N.R. 1987. Empirical Model-Building and Response Surfaces. New York: Wiley.

Brown, S.A., Venkatesh, V., and Goyal, S. 2012. "Expectation Confirmation in Technology Use," Information Systems Research (23:2), pp 474-487.

Brown, S.A., Venkatesh, V., and Goyal, S. 2014. "Expectation Confirmation in Information Systems Research: A Test of Six Competing Models," Mis Quarterly (38:3), pp 729-756.

Brown, S.A., venkatesh, V., Kuruzovich, J., and Massey, A.P. 2008. "Expectation Confirmation: An Examination of Three Competing Models," Organizational Behavior and Human Decision Processes (105), pp 52-66.

Edwards, J.R. 1994. "The Study of Congruance in Organizational Behavior Research: Critique and a Proposed Alternative," Organizational Behavior and Human Decision Processes (58:1), pp 51-100.

Edwards, J.R. 2001. "Alternatives to Difference Scores: Polynomial Regression Analysis and Response Surface Methodology," in: Measuring and Analyzing Behavior in Organizations: Advances in Measurement and Data Analysis, F. Drasgow and N. Schmidt (eds.). San Francisco, CA: Jossey-Bass?Pfeiffer, pp. 350-400.

Edwards, J.R. 2002. "Alternatives to Difference Scores: Polynomial Regeression Analysis and Response Surface Methodology," in: Advances in Measurement and Data Analysis, F. Drasgow and N.W. Schmidt (eds.). San Francisco: Jossey-Bass, pp. 350-400.

Edwards, J.R., and Cooper, C.L. 1990. "The Person-Environment Fit Approach to Stress: Recurring Problems and Some Suggested Solutions," Journal of Organizational Behavior (11:4), pp 293-307.

Edwards, J.R., and Lambert, L.S. 2007. "Methods for Integrating Moderation and Mediation: A General Analytical Framework Using Moderated Path Analysis," Psychological Methods (12:1), pp 1-22.

Edwards, J.R., and Parry, M.E. 1993. "On the Use of Polynomial Regression Equations as an Alternative to Difference Scores in Organizational Research," Academy of Management Journal (36:6), pp 1577-1613.

Edwards, J.R., and Van Harrison, R. 1993. "Job Demands and Worker Health: ThreeDimensional Reexamination of the Relationship between Person-Environment Fit and Strain," Journal of Applied Psychology (78:4), pp 628-648.

Fan, L., and Suh, Y.-H. 2014. "Why Do Users Switch to a Disruptive Technology? An Empirical Study Based on Expectation-Disconfirmation Theory," Information \& Management (51:2), pp 240-248.

Fang, Y., Qureshi, I., Sun, H., McCole, P., Ramsey, E., and Lim, K.H. 2014. "Trust, Satisfaction, and Online Repurchase Intention: The Moderating Role of Perceived Effectiveness of ECommerce Institutional Mechanisms," MIS Quarterly (38:2), pp 407-427. 
Fredricks, A.J., and Dossett, D.L. 1983. "Attitude-Behavior Relations: A Comparison of the Fishbein-Ajzen and the Bentler-Speckart Models," Journal of Personality and Social Psychology (45:3), p 501.

Harris, M.M., Ansaal, F., and Lievens, F. 2008. "Keeping up with the Joneses: A Field Study of the Relationships among Upward, Lateral, and Downward Comparisons and Pay Level Satisfaction," Journal of Applied Psychology (93), pp 665-673.

Hecht, T.D., and Allen, N.J. 2005. "Exploring Links between Polychronicity and Well-Being from the Perspective of Person-Job Fit: Does It Matter If You Prefer to Do Only One Thing at a Time?," Organizational Behavior and Human Decision Processes (98:2), pp 155178.

Hong, Y., and Pavlou, P.A. 2014. "Product Fit Uncertainty in Online Markets: Nature, Effects, and Antecedents," Information Systems Research (25:2), pp 328-344.

Johnston, A.C., Warkentin, M., and Siponen, M. 2015. "An Enhanced Fear Appeal Rhetorical Framework: Leveraging Threats to the Human Asset through Sanctioning Rhetoric," MIS Quarterly (39:1), pp 113-134.

Kahneman, D., and Tversky, A. 1979. "Prospect Theory: An Analysis of Decision under Risk," Econometrica: Journal of the Econometric Society), pp 263-291.

Khuri, A.I., and Cornell, J.A. 1987. Response Surfaces: Designs and Analyses. New York: Marcel Dekker.

Kim, K., Mithas, S., Whitaker, J., and Roy, P.K. 2014. "Research Note-Industry-Specific Human Capital and Wages: Evidence from the Business Process Outsourcing Industry," Information Systems Research (25:3), pp 618-638.

Kim, S.K., and Hsieh, P.-H. 2003. "Interdependence and Its Consequences in DistributorSupplier Relationships: A Distributor Perspective through Response Surface Approach," Journal of Marketing Research (40:1), pp 101-112.

Kristof, A.L. 1996. "Person-Organization Fit: An Integrative Review of Its Conceptualizations, Measurement, and Implications," Personnel Psychology (49:1), pp 1-49.

Lankton, N., McKnight, D.H., and Thatcher, J.B. 2014. "Incorporating Trust-in-Technology into Expectation Disconfirmation Theory," The Journal of Strategic Information Systems (23:2), pp 128-145.

Lankton, N.K., and McKnight, H.D. 2012. "Examining Two Expectation Disconfirmation Theory Models: Assimilation and Asymmetry Effects," Journal of the Association for Information Systems (13:2), pp 88-115.

Li, T., Kauffman, R.J., Van Heck, E., Vervest, P., and Dellaert, B.G. 2014. "Consumer Informedness and Firm Information Strategy," Information Systems Research (25:2), pp 345-363.

Lim, S., Saldanha, T.J., Malladi, S., and Melville, N.P. 2013. "Theories Used in Information Systems Research: Insights from Complex Network Analysis," Journal of Information Technology Theory and Application (JITTA) (14:2), p 2. 
Ma, X., Kim, S.H., and Kim, S.S. 2014. "Online Gambling Behavior: The Impacts of Cumulative Outcomes, Recent Outcomes, and Prior Use," Information Systems Research (25:3), pp 511527.

Maruping, L.M., and Magni, M. 2015. "Motivating Employees to Explore Collaboration Technology in Team Contexts," MIS Quarterly (39:1), pp 1-16.

McCullagh, P., Nelder, J.A., and McCullagh, P. 1989. Generalized Linear Models. Chapman and Hall London.

McKinney, V., Yoon, K., and Zahedi, F.M. 2002. "The Measurement of Web-Customer Satisfaction: An Expectation and Disconfirmation Approach," Information Systems Research (13:3), September, pp 296-315.

Meservy, T.O., Jensen, M.L., and Fadel, K.J. 2013. "Evaluation of Competing Candidate Solutions in Electronic Networks of Practice," Information Systems Research (25:1), pp 1534 .

O'Leary, M.B., Wilson, J.M., and Metiu, A. 2014. "Beyond Being There: The Symbolic Role of Communication and Identification in Perceptions of Proximity to Geographically Dispersed Colleagues," MIS Quarterly (38:4), pp 1219-1243.

Oliver, R.L. 1977. "Effect of Expectation and Disconfirmation on Postexposure Product Evaluations: An Alternative Interpretation," Journal of Applied Psychology (62:4), pp 480486.

Oliver, R.L. 1980. "A Cognitive Model of the Antecedents and Consequences of Satisfaction Decisions," JMR, Journal of Marketing Research (17:4), pp 460-460.

Oliver, R.L., Balakrishnan, P.V.S., and Barry, B. 1994. "Outcome Satisfaction in Negotiation: A Test of Expectancy Disconfirmation," Organizational Behavior and Human Decision Processes (60:2), pp 252-275.

Ping, R.A. 2002. "Interpreting Latent Variable Interactions," American Marketing Association (Winter) Educators' Conference Proceedings, Austin, TX, pp. 213-220.

Roberts, N., and Grover, V. 2012a. "Investigating Firm's Customer Agility and Firm Performance: The Importance of Aligning Sense and Respond Capabilities," Journal of Business Research (65:5), pp 579-585.

Roberts, N., and Grover, V. 2012b. "Leveraging Information Technology Infrastructure to Facilitate a Firm's Customer Agility and Competitive Activity: An Empirical Investigation," Journal of Management Information Systems (28:4), pp 231-270.

Scherer, A., Wünderlich, N.V., and Von Wangenheim, F. 2015. "The Value of Self-Service: Long-Term Effects of Technology-Based Self-Service Usage on Customer Retention," MIS quarterly (39:1), pp 177-200.

Shanock, L., Baran, B., Gentry, W., Pattison, S., and Heggestad, E. 2010. "Polynomial Regression with Response Surface Analysis: A Powerful Approach for Examining Moderation and Overcoming Limitations of Difference Scores," Journal of Business and Psychology (25:4), pp 543-554.

Shaw, J.D., and Gupta, N. 2004. "Job Complexity, Performance, and Well-Being: When Does Supplies-Values Fit Matter?" Personnel Psychology (57:4), pp 847-879. 
Steelman, Z.R., Hammer, B.I., and Limayem, M. 2014. "Data Collection in the Digital Age: Innovative Alternatives to Student Samples," MIS Quarterly (38:2), pp 355-378.

Sykes, T.A., Venkatesh, V., and Johnson, J.L. 2014. "Enterprise System Implementation and Employee Job Performance: Understanding the Role of Advice Networks," MIS Quarterly (38:1), pp 51-72.

Tabachnick, B.G., and Fidell, L.S. 2007. Using Multivariate Statistics. Boston: Allyn and Bacon.

Titah, R., and Barki, H. 2009. "Nonlinearities between Attitude and Subjective Norms in Information Technology Acceptance: A Negative Synergy?," MIS Quarterly (33:4), pp 827-844.

Tversky, A., and Kahneman, D. 1973. "Availability: A Heuristic for Judging Frequency and Probability," Cognitive psychology (5:2), pp 207-232.

Venkatesh, V., and Goyal, S. 2010. "Expectation Disconfirmation and Technology Adoption: Polynomial Modeling and Response Surface Analysis," MIS Quarterly (34:2), pp 281-303.

Xu, J.D., Benbasat, I., and Cenfetelli, R.T. 2014. "The Nature and Consequences of Trade-Off Transparency in the Context of Recommendation Agents1," MIS Quarterly (38:2), pp 379406. 


\section{Appendix A: Possible applications of polynomial regression and response surface methodology on the papers published in MISQ and ISR}

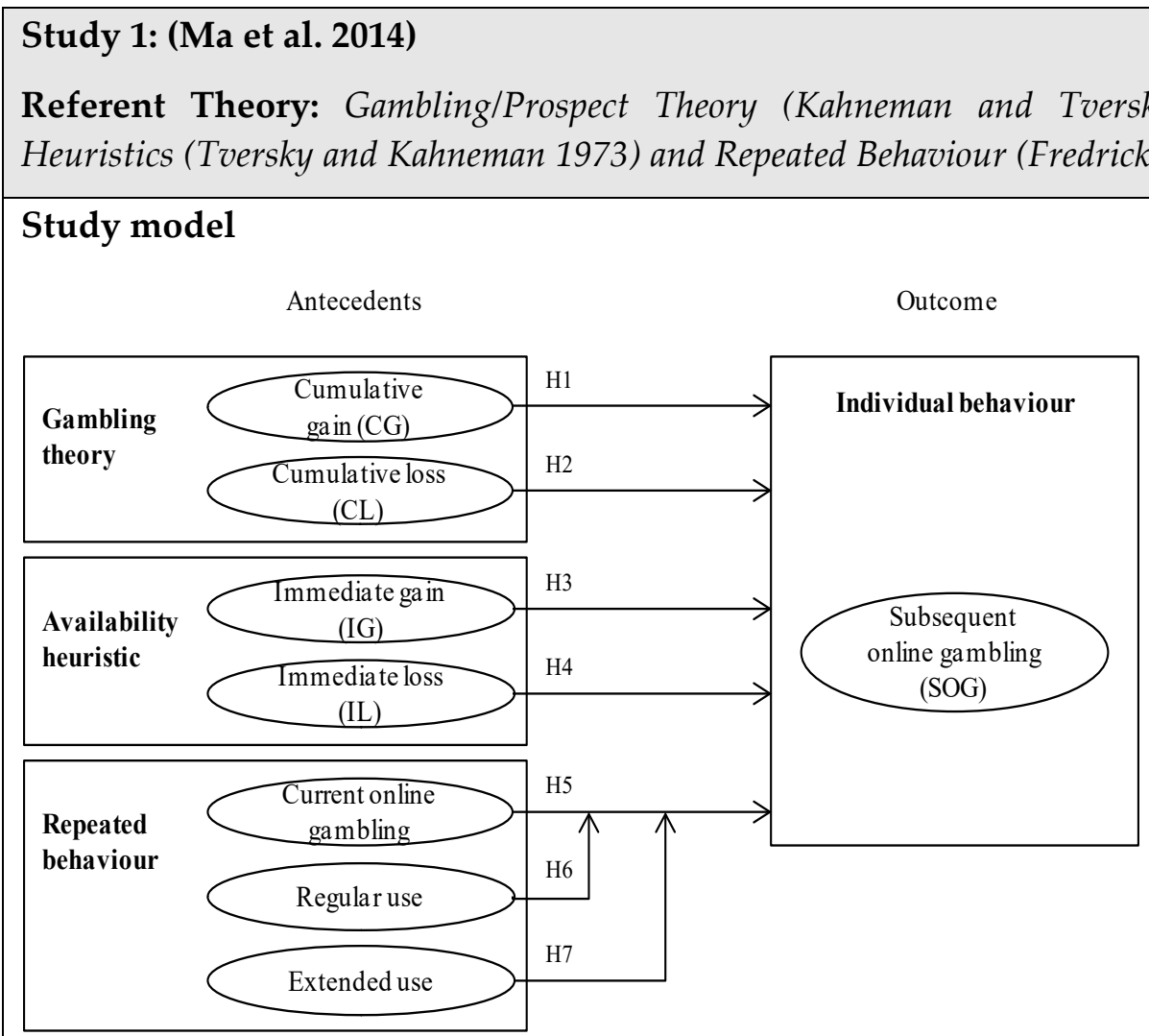

Possible applications of polynomial regression and response surface methodology

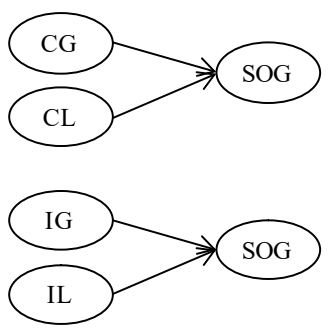

The three theoretical propositions used for the conceptual model development suggest non-linearities. The response surfaces could complement the discussion by providing insights into how different combinations of predictor variables (e.g., two types of gains and losses) influence the online gambling behaviour. Also, with two response surfaces for current online gambling, regular use (or extended use) and subsequent online gambling could provide deeper insights into the nature of interference that the two types of use has on the relationship between current online gambling and subsequent online gambling behaviour. Polynomial regression and response surface methodology allows the investigation of how two sets of predictor variables, (i) cumulative gain and cumulative loss, and (ii) immediate gain and immediate loss individually as well as in combination influence the dependent variable - subsequent online gambling behaviour. The method also facilitates the understanding of how different combinations of predictor variables influence the outcome variable. 


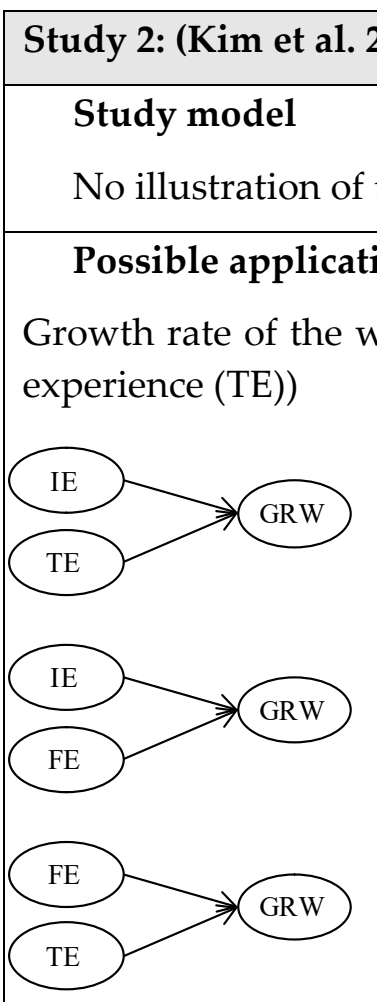

Theoretical model suggests that the growth rate of the wages is a function of industry experience, firm specific experience and total experience. Also, it depicts the rate of change is not constant as the experience increases, thus suggest non-linearity. Polynomial regression can create three different response surfaces for different combinations of three types of experiences and growth rate of wages, thus could provide insights into what combinations of experience would yield better (worse) growth rates of wages. Three different response surfaces for different combinations of three types of experiences and growth rate of wages can complement the discussion by what combinations of experience would yield better (worse) growth rates of wages. 

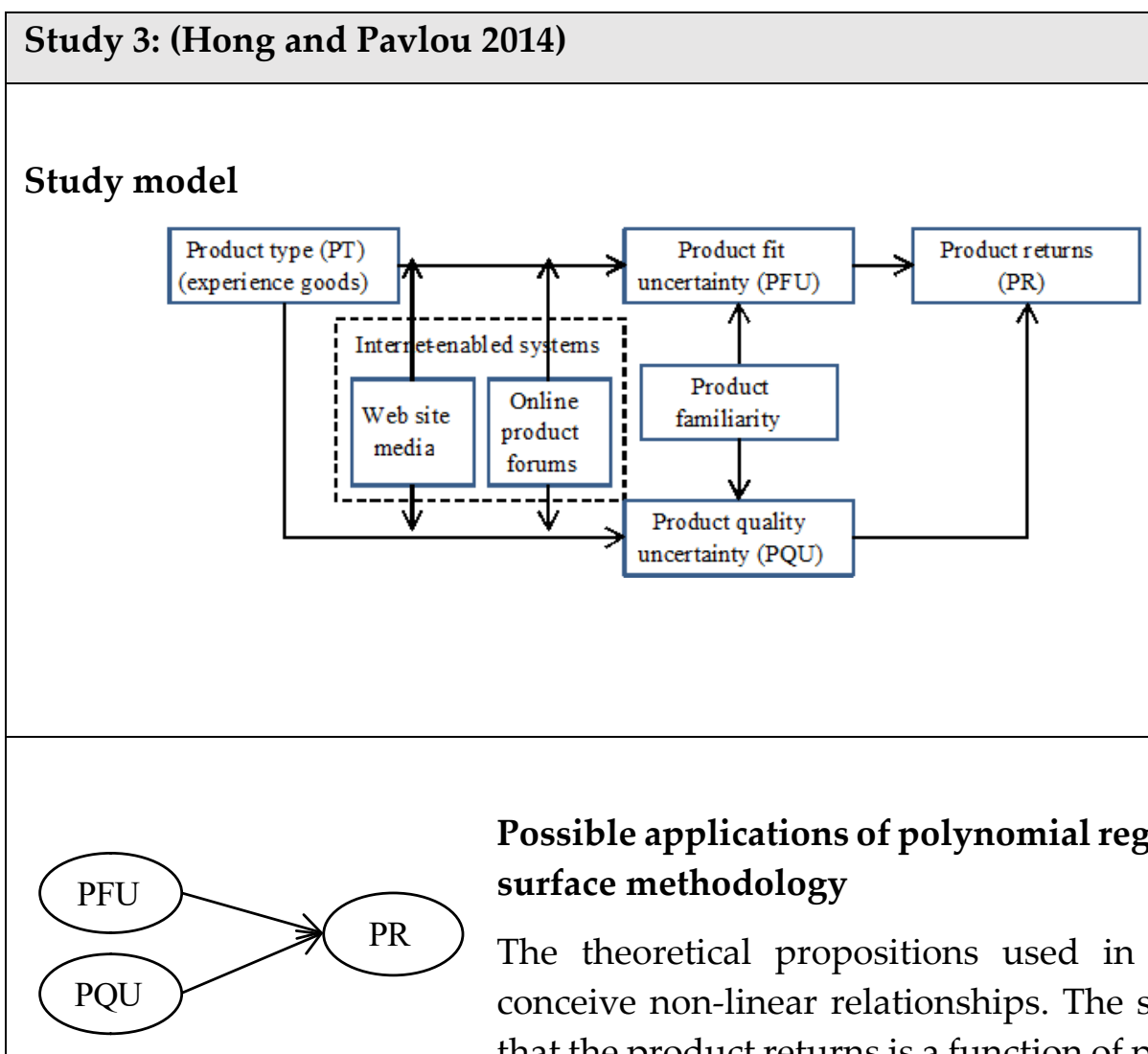

Possible applications of polynomial regression and response surface methodology

The theoretical propositions used in deriving the model conceive non-linear relationships. The study model suggests that the product returns is a function of product fit uncertainty and product quality uncertainty. The application of a response surface to test the interaction effects between product fit uncertainty (PFU) and product quality uncertainty (PQU) on product returns (PR) would have provided insights into how different combinations of PFU and PQU influence the PR and optimum combination of PFU and PQU that ensure the least amount of PR. Also, the response surface methodology has the potential to provide information relating to what degree of PFU and PQU is most critical for PR. A response surface for product fit uncertainty, product quality uncertainty, and product returns would complement the discussion by providing insights into how different combinations influence the product returns and optimum combination. This ensures the least amount of product returns. 
Study 4: (Li et al. 2014)

\section{Study model:}

The model is developed based on discrete choice model. However, no illustration of the research model was presented in the paper.

The theoretical propositions used to theorize the consumer informedness - the price and the product, and the two consumer behaviours - the trading out and trading down, do not conceive linear relationships between constructs. Response surfaces for two types of informedness, on types of consumer behaviours for two segments of products would have complemented the discussion by providing visual representations thus making the comparisons easier to comprehend. In addition, the response surface methodology has the potential to provide insights into how different combinations of two predictor variables influence the two forms of consumer behaviours.

Possible applications of polynomial regression and response surface methodology:

Customers sensitivity (CS) $=f$ (price informedness (Pri-I), product informedness (Pro-I))

A response surface would complement the discussion by providing different combinations of product and price informedness that influence customer sensitivity. 


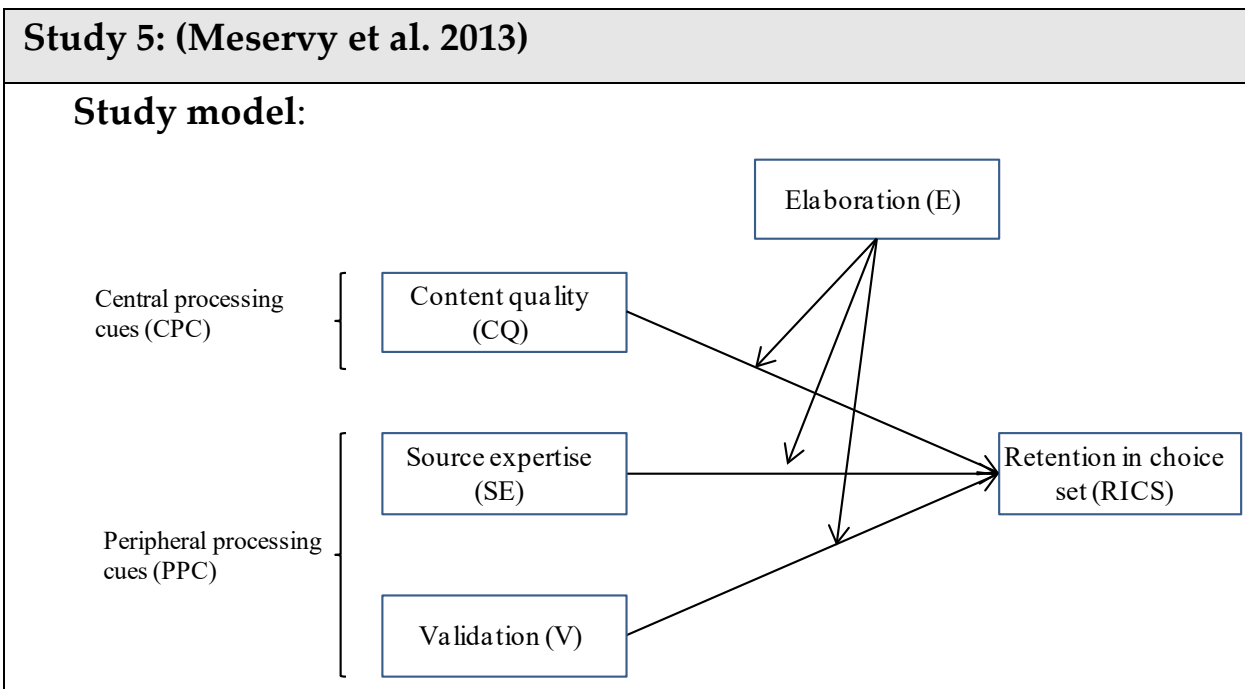

\section{Possible applications of polynomial regression and response surface methodology:}
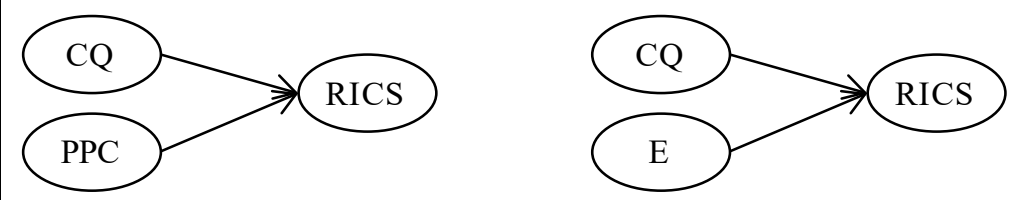

The study evaluates how two types of knowledge evaluations - the central and
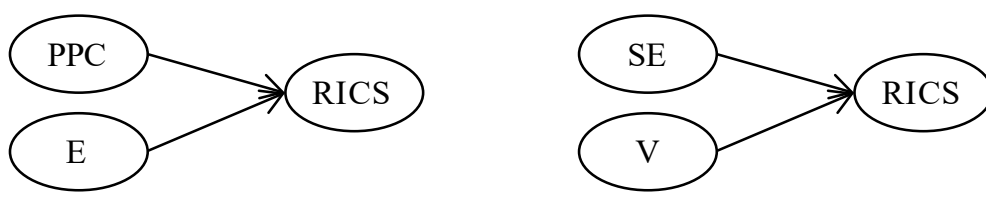
peripheral - influences the knowledge filtering decisions. The study utilizes a repeated generalized linear model that
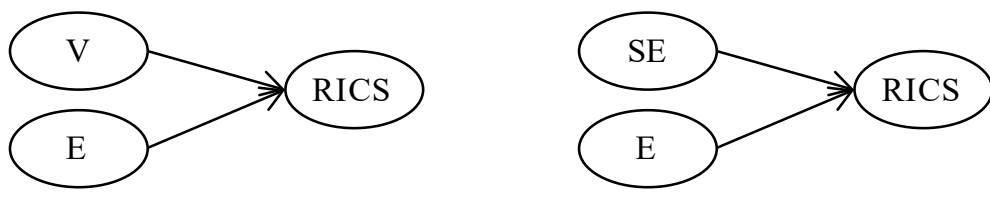
uses quasi likelihood function to model predictor variables effects (McCullagh et al. 1989). As the theoretical grounding hints non-linearities, by applying polynomial regression together with response surface methodology, the analysis would have unearthed deep insights into how the interactions between different processing cues would differently influence the knowledge filtering decisions. Such analysis also could provide insights into how elaboration mediates/moderates the relationships between each type of processing cues and the knowledge filtering decisions. With six response surfaces comprising of five key constructs in the model could have aided a rich discussion on how different magnitudes of each element influence consumers choice set. 


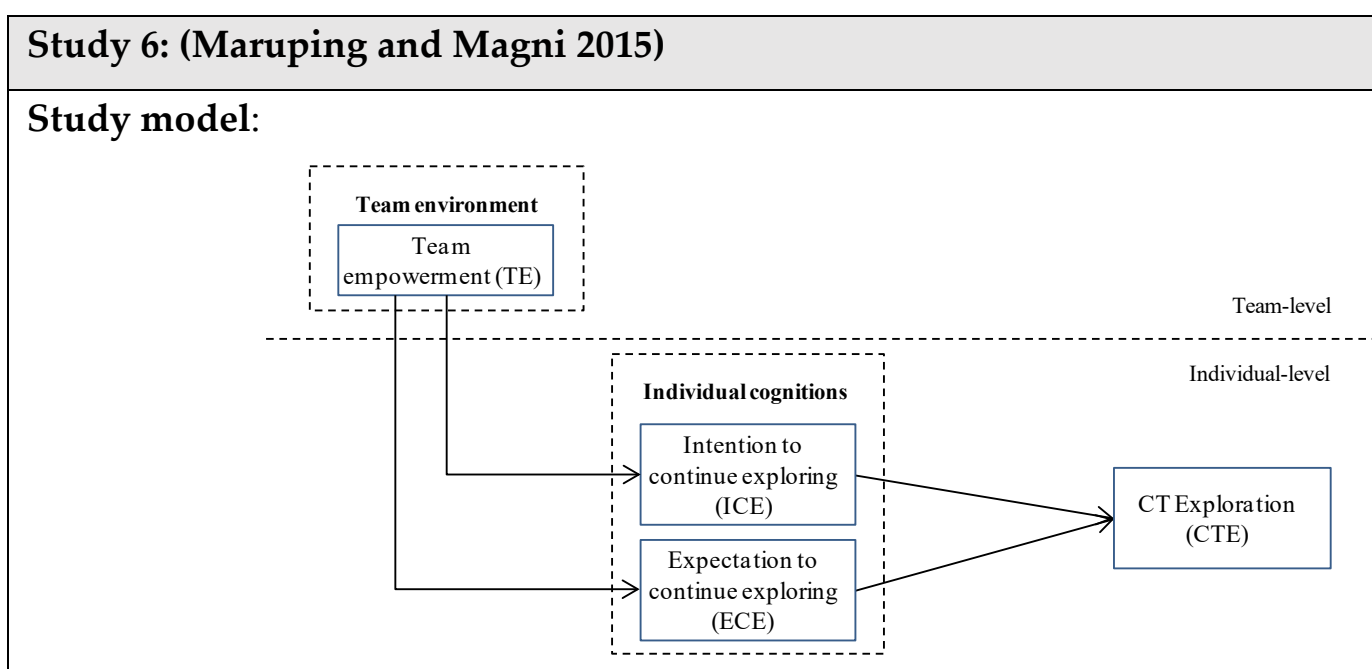

Possible applications of polynomial regression and response surface methodology
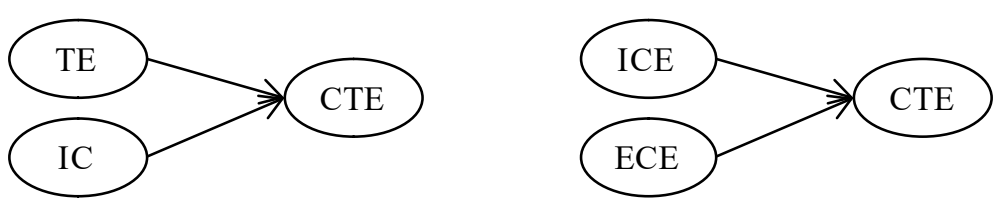

The theories used to develop the conceptual model involving two types of individual cognitions: Intention and expectations, Exploration all suggest non-
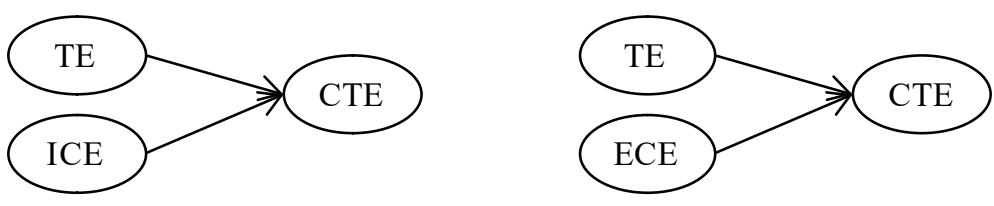
linear relationships between the constructs. Also, the model conceived as exploration is a function of both intention and expectations. As such the model tested for both linear and non-linear mixed-effects yet polynomial regression and response surface methodology were overlooked. However, the inclusion of polynomial regression together with response surface methodology would have enriched the discussion by providing insights into (i) how the interaction effect of intention and expectations influences exploration, and (ii) how different combinations of intention and expectations differently influences the exploration behaviour. Four different response surfaces for four tripartite relationships above between four key constructs in the research model can complement the overall discussion with providing insights into how varying levels of team empowerment influence two kinds of human cognitions thus the varying degree of two forms of cognitions mediates CT exploration behaviour. 


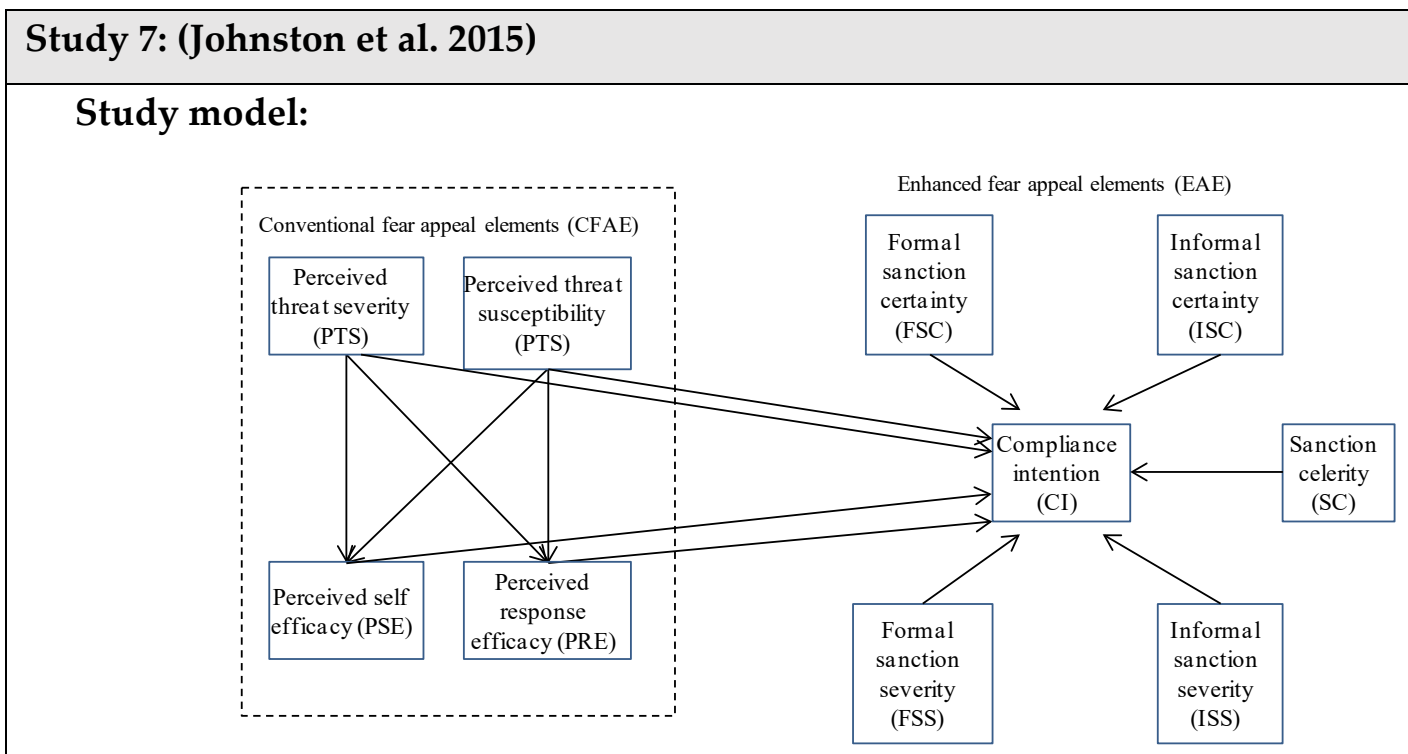

\section{Possible applications of polynomial regression and response surface methodology:}
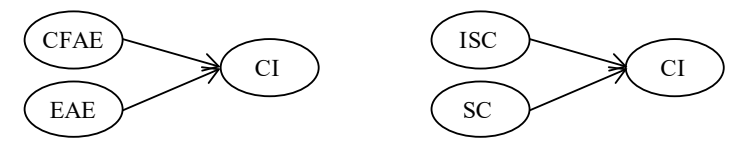

Whilst the conceptual model predicts the behaviour of compliance intention, the theories used in development of conceptual model
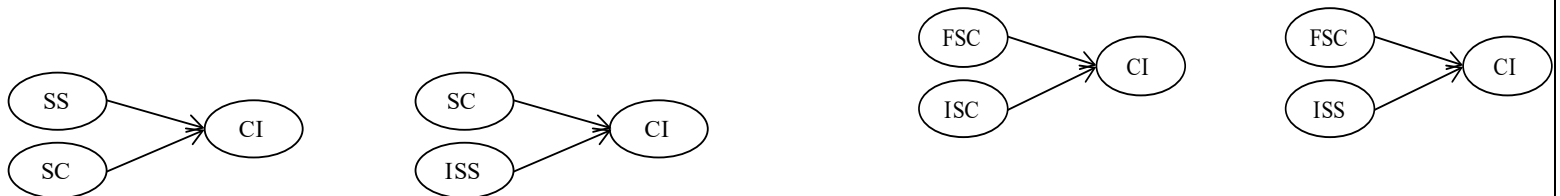

conceive non-linear relationships between the constructs. The behaviour of fear appeal is conceived as a function of the two types of fear appeal elements - conventional and enhanced, whilst the two types of
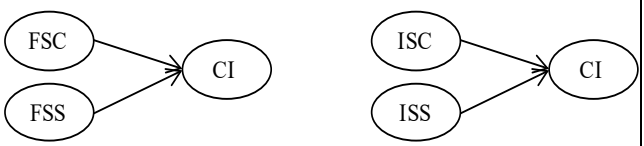
fear appeal elements are consisting of number of different sub-components. Thus, derivation of three-dimensional response surfaces for many different tripartite relationships between different components of the study model such as types of sanctions, severity, certainty and celerity of them, perceived threat severity and susceptibility, perceived selfefficacy and response efficacy are possible. Such an exercise has a greater potential to unearth complex relationships, nuanced views of such relation4ships and deep insights into how different combinations of different elements and different magnitudes of two types of fear appeal elements in combination influences an individual's compliance intention. Twelve tripartite relationships between the different types of constructs in the study model may have complemented the discussion allowing the researchers to discuss how different magnitudes of two types of fear appeal elements in combination define an individual's compliance intention.
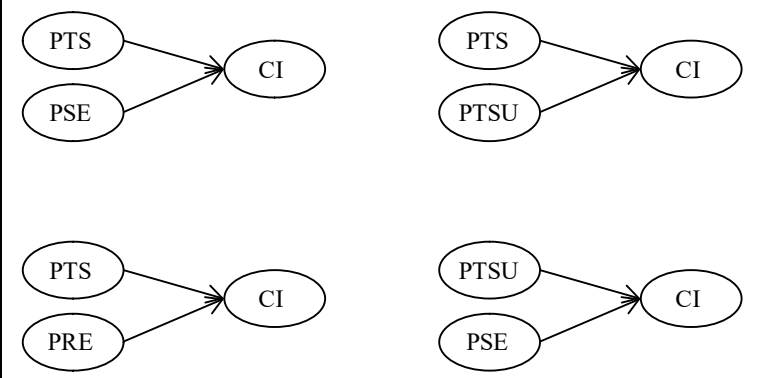


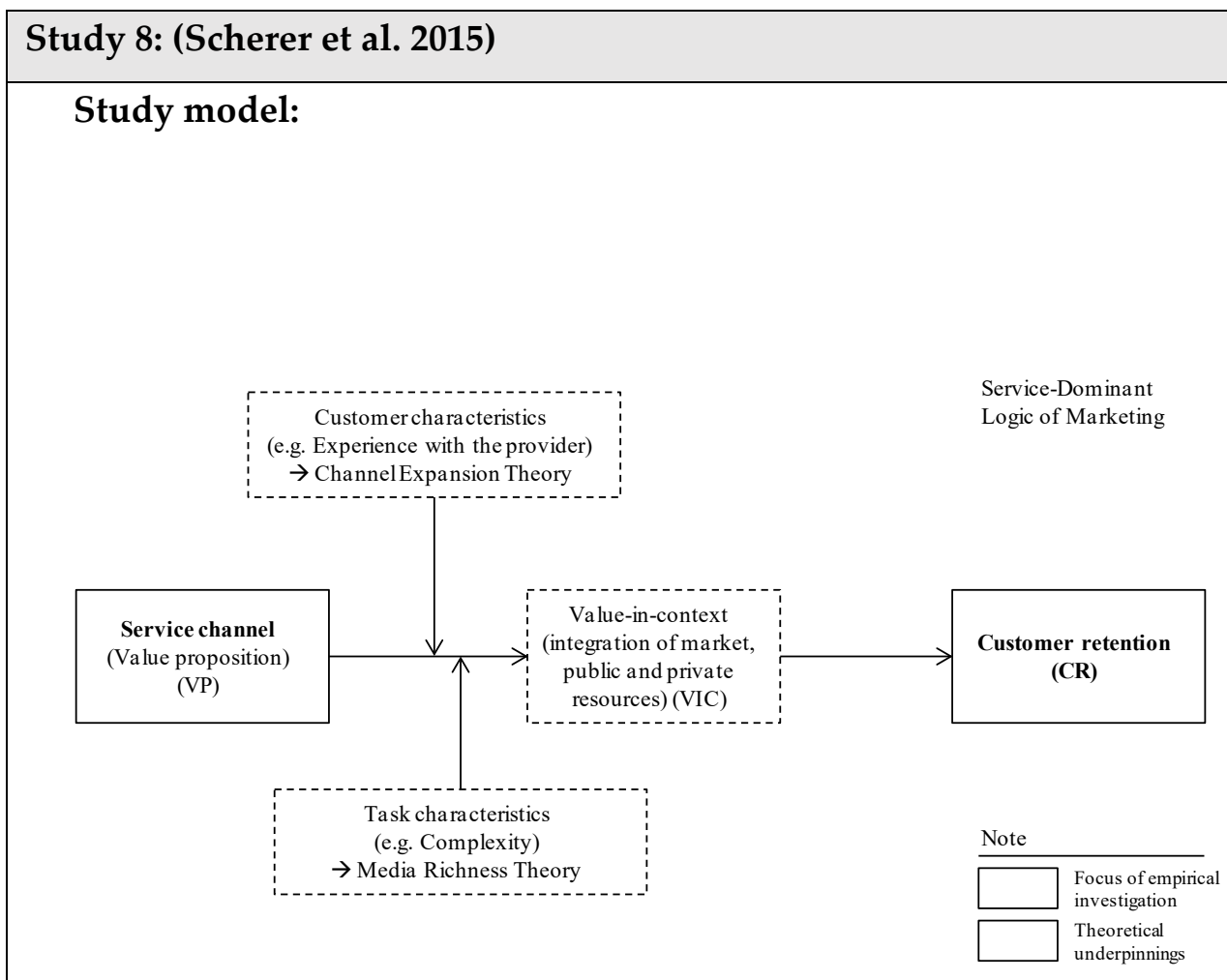

Possible applications of polynomial regression and response surface methodology:

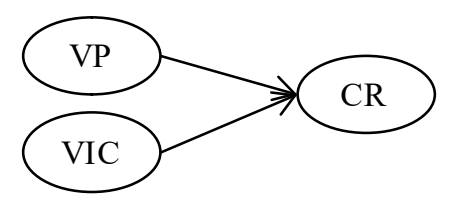

The objective of the study is to investigate how the ratio of self-service versus personal service use influence customer defection/retention over time. Whilst the theories underlying the theoretical model supports non-linear relationships between the constructs, a response surface created through a polynomial regression would have complemented the discussion by providing insights into how different combinations of self service and personal service together influence customer defection/retention. A response surface created through a polynomial regression would have provided insights into how varying degree of value proposition and value-in-context in combination assure customer retention. In addition, the response surface has the potential to explain the nature of mediation that value-in-context play on the relationship between value proposition and customer retention. 


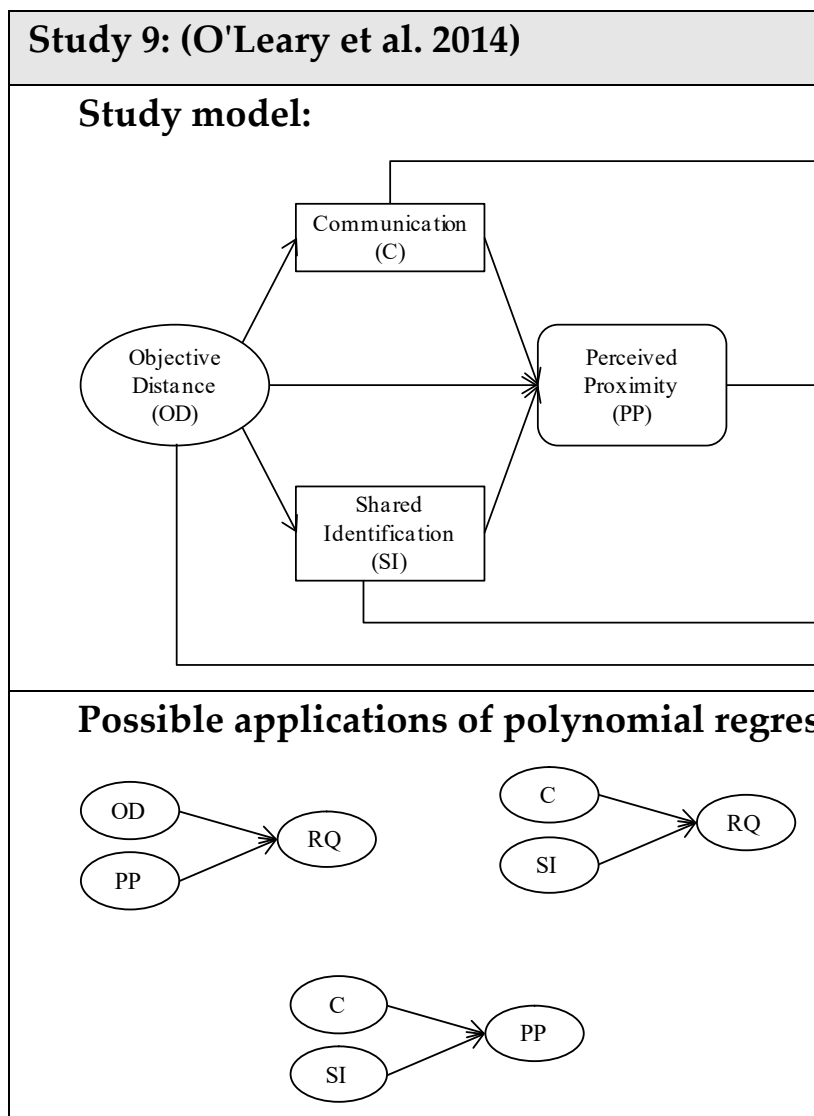

The paper investigates how perceived proximity-cognitive and affective sense of relational closeness and objective distancegeographical closeness, relate to relationship quality for collocated and geographically dispersed work colleagues. Whilst the underlying theoretical propositions suggest non-linearities a response surface methodology has the potential to complement the analysis by providing further insights into how different combinations of perceived and objective proximities together would differently influences the quality of the overall relationship. Further, such an analysis could provide deep insights in to how perceived proximity is mediating the relationship between objective distance and relationship quality (or contrariwise). Also, establishing two different response surfaces for the tripartite relationships between (i) objective distance, shared identification, and perceived proximity, and (ii) objective distance, communication and perceived proximity have the ability to provide insights into how different degrees of communication and shared identification mediate the relationship between objective distance and perceived proximity thus its overall influence the relationship quality. Two different response surfaces for the tripartite relationships between shared identification, communication, perceived proximity and relationship quality can complement the analysis by providing how different combinations of communication and shared identification influence perceived proximity and relationship quality. Similarly, a response surface for objective distance, perceived proximity and relationship can explain how perceived proximity is mediating the relationship between objective distance and relationship quality. 


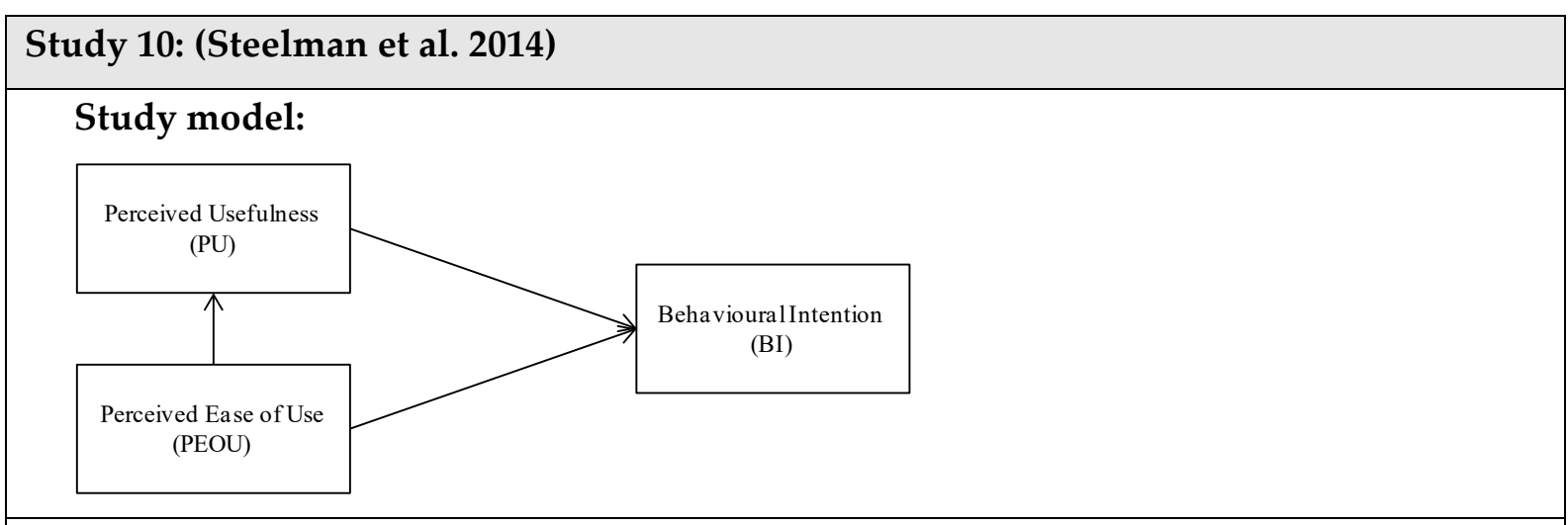

\section{Possible applications of polynomial regression and response surface methodology:}

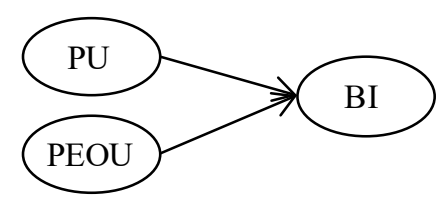

The aim of this paper is to examine the consistency of survey responses across different samples obtained from different cohorts of respondents across two different studies involving original TAM model and EDT. Whilst both TAM and EDT in their original conceptions predict non-linear relationships between the constructs both models conceive that the respective dependent variables behavioural intention and satisfaction. Use of response surfaces between the three key variables in TAM and ECT across five different samples in the study would have complemented the structural model comparisons using PLS. This can be done by visually exhibiting the similarities and/or contrasting the differences much effectively across the samples used in the analysis. Such response surfaces have the potential to provide further insights into how different proportions of two predictor variables are impacting the dependent variable similarly of differently across different cohorts of samples. Same model can be tested across student sample, worldwide OCM sample, US OCM sample, Non-US OCM sample and the consumer sample. Response surfaces between the three key variables of the research model across five different samples would have complemented the structural model results using PLS, as response surface methodology has the potential to visually exhibit the similarities and/or contrast differences better across the samples used in the analysis. 


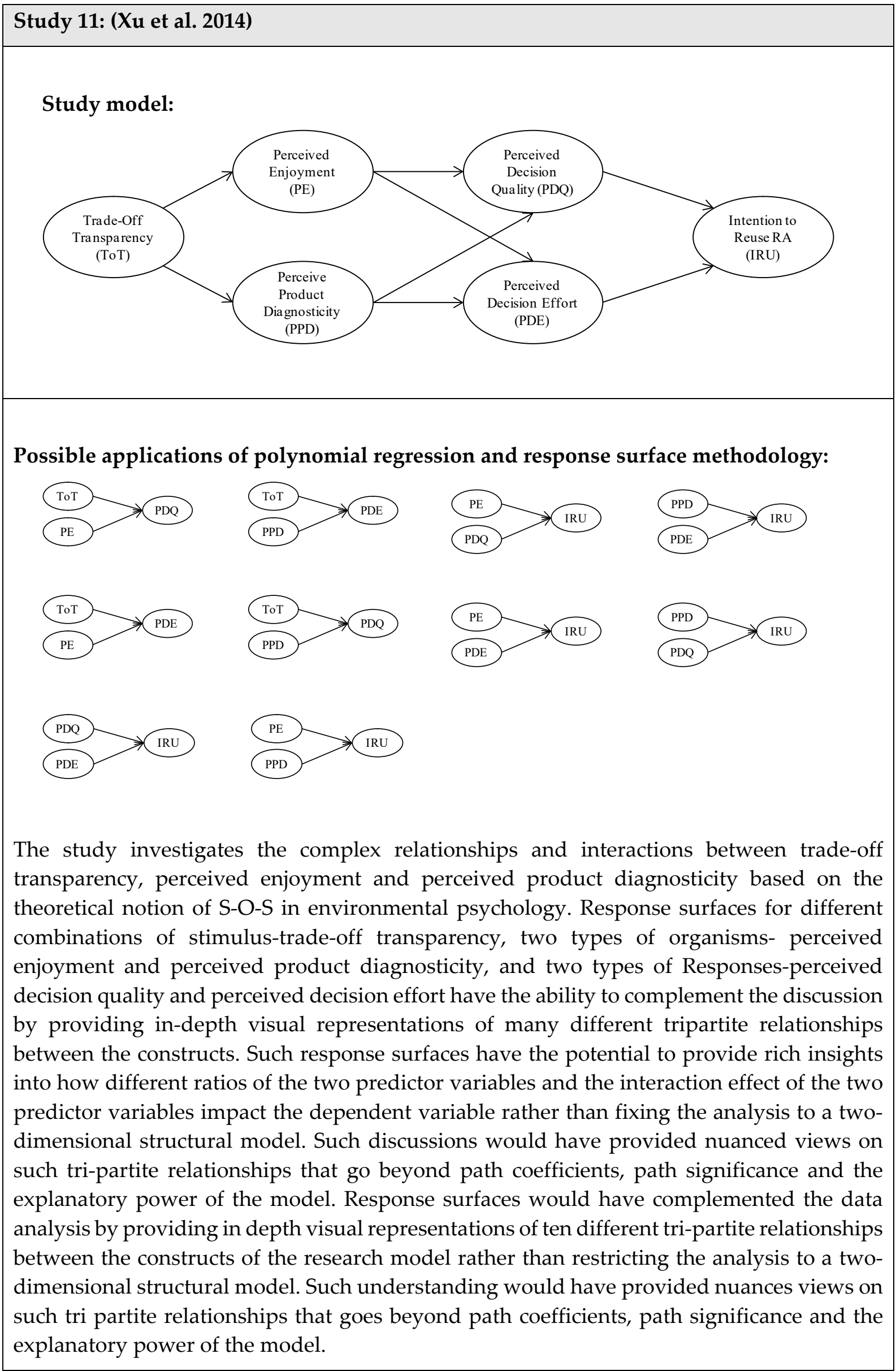




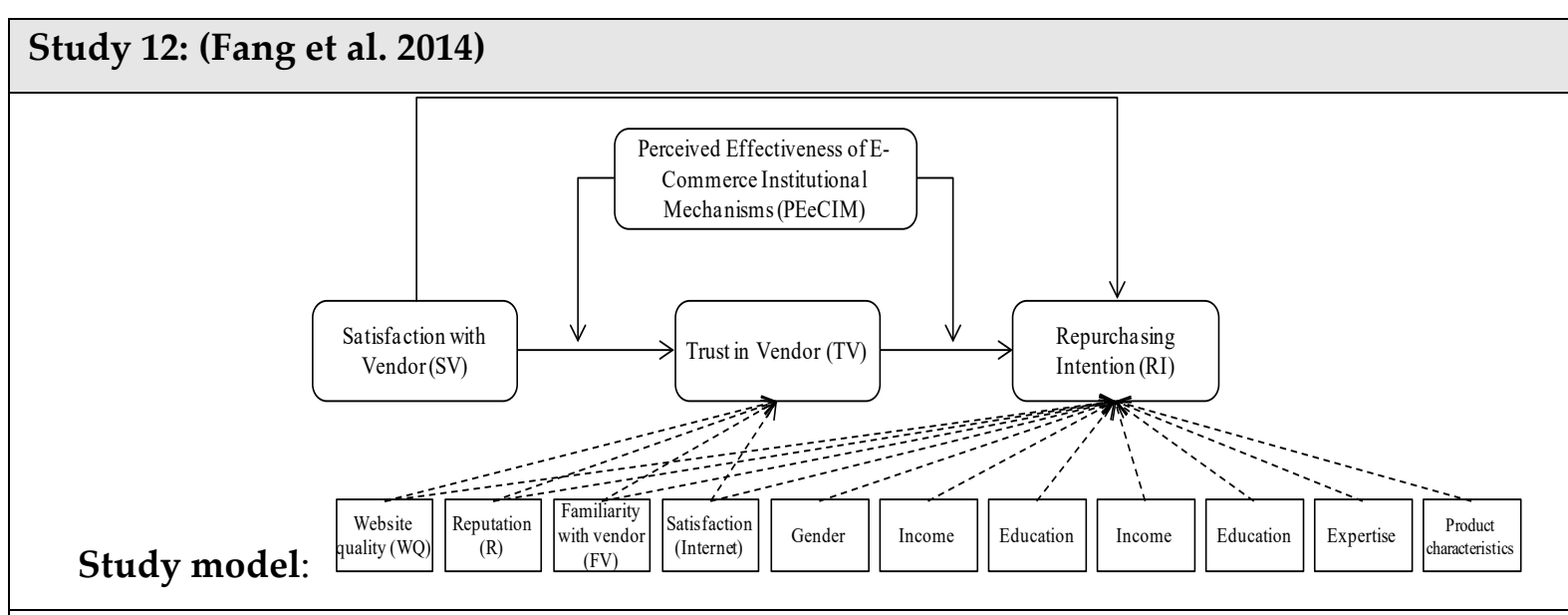

Possible applications of polynomial regression and response surface methodology:

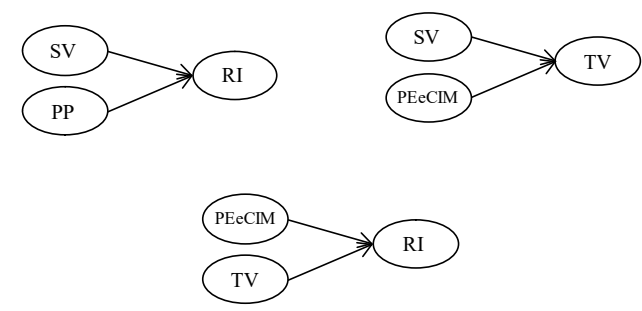

Based on the theory of organizational trust this study investigates how the perceived effectiveness of e-commerce institutional mechanisms moderate the trust, satisfaction and online purchase intention relationship. Response surfaces among four key variables involving perceived effectiveness of e-commerce institutional mechanisms, trust, satisfaction and online purchase intention have the potential to provide further insights. For example, it can provide insights into how the magnitude of trust in vendor and perceived effectiveness of e-commerce institutional mechanisms mediate and moderate the relationship between satisfaction with vendor and repurchasing intentions that go beyond the traditional structural model testing. Response surfaces of three tripartite relationships between four key variables of the research model would enable how the magnitude of trust in vendor and perceived effectiveness of e-commerce institutional mechanisms mediate and moderate the relationship between satisfaction with vendor and repurchasing intentions. 


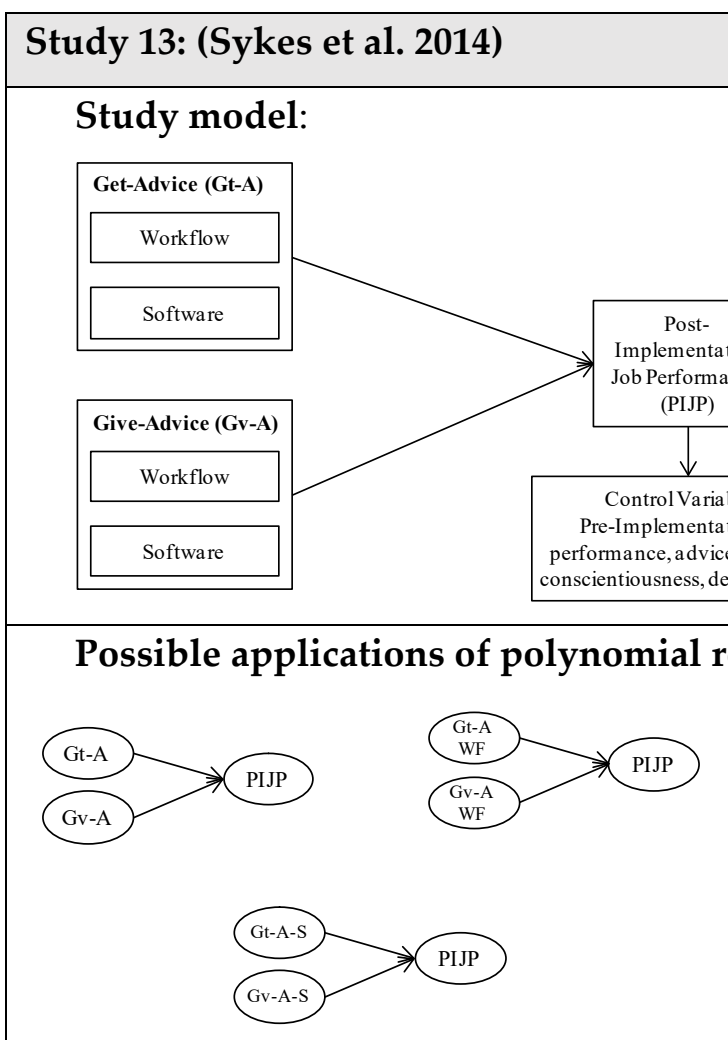

Key objectives of the study are to understand the interaction effects between two types of advices get-advice and give-advice on software and workflows on post implementation job performance. Thus, the data was collected in four types of socio matrices: workflow get-advice, workflow give-advice, and software get-advice and software give-advice. The data was analysed using hierarchical regression. Whilst the hierarchical regression can test the interaction effects between the different types of socio matrices on post implementation job performance it would provide detailed insights into how the combinations of different intensities of socio matrices differently influences the post implementation job performance. However, response surface methodology has the potential to add an additional perspective of how varying degrees of four different socio matrices influences the post implementation job performance. Importantly the response surface methodology can provide insights into the best combination/s of the two predictor variables that could produce optimal post-implementation job performance. Response surface methodology would add an additional perspective of how varying degrees of get-advice and give-advice influences the post implementation job performance. 


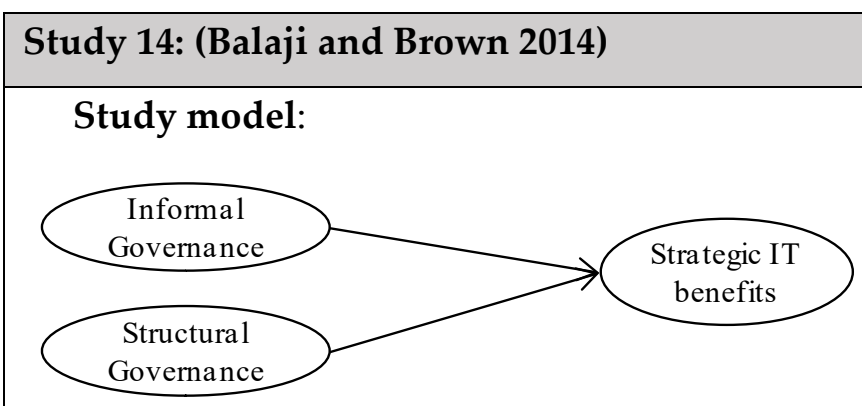

Taking the organization design theory, the paper investigates how two types of lateral coordination mechanisms formal structural and non-structural informal mechanisms, relates to strategic IT benefits to the client firm in IS development outsourcing context. Through the creation of a response surface for the tri-partite relationship between two forms of lateral coordination mechanisms and strategic IT benefits, the discussion could be extended to discuss how different intensities of the two types of lateral coordination mechanisms work together to deliver different types and levels of strategic IT benefits to the client organizations. Further the response surface has the potential to inform the optimum combination of the two coordination mechanisms for different levels of resource provisioning and different value similarity groups. Run the model for different samples of: (1) Low resource provisioning, (2) High resource provisioning, (3) Low value similarity, and (4) High value similarity. Response surfaces created for the tri-partite relationship between the three main constructs of the paper across polarised samples can provide insights into how different degrees of the two types of governance mechanisms work together to deliver the strategic IT benefits. Further the response surface has the potential to inform the optimum combination of the two governance mechanisms that are useful in four distinct resource and value similarity groups.

Copyright: (C) 2019 Sedera \& Atapattu. This is an open-access article distributed under the terms of the Creative Commons Attribution-NonCommercial 3.0 Australia License, which permits non-commercial use, distribution, and reproduction in any medium, provided the original author and AJIS are credited.

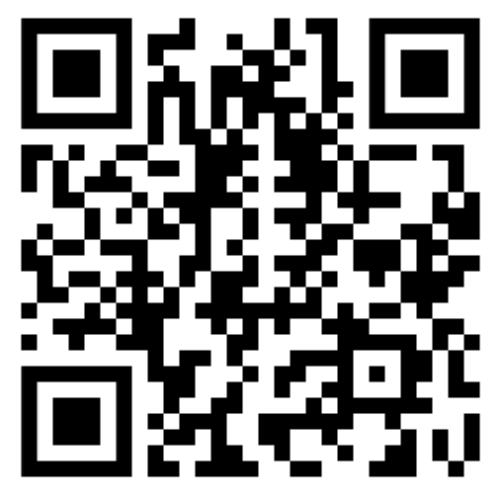

